\title{
Human ex vivo spinal cord slice culture as a useful model of neural development, lesion, and allogeneic neural cell therapy
}

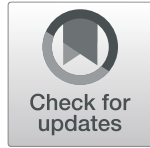

Chenhong Lin ${ }^{1 \dagger}$, Cinzia Calzarossa ${ }^{1,2+}$, Teresa Fernandez-Zafra ${ }^{3}$, Jia Liư ${ }^{1,4}$, Xiaofei Li ${ }^{1}$, Åsa Ekblad-Nordberg ${ }^{5}$, Erika Vazquez-Juarez ${ }^{1}$, Simone Codeluppi ${ }^{3}$, Lena Holmberg ${ }^{1}$, Maria Lindskog ${ }^{1}$, Per Uhlén ${ }^{3}$ and Elisabet Åkesson ${ }^{1,6^{*}}$ (D)

\begin{abstract}
Background: There are multiple promising treatment strategies for central nervous system trauma and disease. However, to develop clinically potent and safe treatments, models of human-specific conditions are needed to complement in vitro and in vivo animal model-based studies.
\end{abstract}

Methods: We established human brain stem and spinal cord (cross- and longitudinal sections) organotypic cultures (hOCs) from first trimester tissues after informed consent by donor and ethical approval by the Regional Human Ethics Committee, Stockholm (lately referred to as Swedish Ethical Review Authority), and The National Board of Health and Welfare, Sweden. We evaluated the stability of hOCs with a semi-quantitative hOC score, immunohistochemistry, flow cytometry, $\mathrm{Ca}^{2+}$ signaling, and electrophysiological analysis. We also applied experimental allogeneic human neural cell therapy after injury in the ex vivo spinal cord slices.

Results: The spinal cord hOCs presented relatively stable features during 7-21 days in vitro (DIV) (except a slightly increased cell proliferation and activated glial response). After contusion injury performed at 7 DIV, a significant reduction of the hOC score, increase of the activated caspase- $3^{+}$cell population, and activated microglial populations at 14 days postinjury compared to sham controls were observed. Such elevation in the activated caspase- $3^{+}$population and activated microglial population was not observed after allogeneic human neural cell therapy.

Conclusions: We conclude that human spinal cord slice cultures have potential for future structural and functional studies of human spinal cord development, injury, and treatment strategies.

Keywords: Spinal cord injury, Stem cell therapy, Human organotypic culture

\section{Background}

Human central nervous system (CNS) lesions, such as spinal cord injury (SCI), present limited spontaneous regenerative properties and largely lack available treatments offering functional improvement. Numerous and

\footnotetext{
* Correspondence: elisabet.akesson@ki.se

${ }^{+}$Chenhong Lin and Cinzia Calzarossa shared first authorship.

'Department of Neurobiology, Care Sciences and Society, Div. of

Neurogeriatrics, Karolinska Institutet, Stockholm, Sweden

${ }^{6}$ The R\&D Unit, Stockholms Sjukhem, Stockholm, Sweden

Full list of author information is available at the end of the article
}

often promising pre-clinical studies with various neuroprotective compounds, factors supporting regeneration as well as cell therapies have led to multiple clinical trials [1-4]. However, translation from experimental animal models to the clinical settings has proven to be challenging.

State-of-the-art treatment for traumatic SCI aims to limit the lesion to a minimum but neural regeneration and functional recovery after SCI is still limited. Neural cell therapy represents one experimental treatment strategy to support structural and functional improvement 
after SCI with promising and significant results in SCI animal models [5-9]. Recently, human allogeneic neural cell therapy clinical trials in chronic SCI $[10,11]$ presented feasibility and tolerability. However, statistical power and control groups are missing often due to ethical reasons. Therefore, to improve treatment efficacy and ensure safety, we need model systems mimicking human nervous system lesions and allogeneic conditions as closely as possible to elucidate mechanisms involved in injury progression as well as neuroprotection and repair.

In vivo animal models permit the study of complex interactions between multiple organ systems. However, using animal studies alone is not sufficient to understand human biology and pathology. Compared to regular cell culture, ex vivo tissue slice culture provides at least partly maintained original tissue architecture with some intact functional neural networks [12]. Ex vivo slice cultures are relatively easy to establish and can be utilized in short-(days) as well as long-(weeks) term experiments. Moreover, they may recapitulate or mimic lesion pathology, allowing the study of pathological and regenerative pathways in tissue-like complexity [13, 14]. Therefore, an established human nervous system slice culture model would allow promising repair strategies including gene $[15,16]$ as well as neural cell therapeutic approaches [17-20] to be pre-clinically tested in human conditions. Thus, as a complementary method (allowing human spinal cord study, while reducing costs and resource demands in addition to animal use), human slice culture, when available, is of value.

So far, CNS slice culture with tissue from embryonic, postnatal, and adult stages has mainly been utilized in rodents. Both cross-sectional and longitudinal organotypic slice cultures from animal spinal cord have been developed [21-26] and used to study SCI [27-29] and cell therapy [17-20]. However, to develop treatment strategies for human SCI, studies of species-specific anatomical, physiological, and immunological features [30-32] are central $[33,34]$ and should be further utilized.

In this paper, we have developed a human ex vivo spinal cord slice culture model and described a method to evaluate such cultures in vitro. With the present protocol, we report longitudinal and cross-sectional human tissue slice cultures of the spinal cord with markedly consistent organotypic structural features after 721 days in vitro (DIV). We also confirmed their viability by $\mathrm{Ca}^{2+}$ signaling and electrophysiological analysis. To further use the model, we performed in vitro slice contusion injury and studied allogeneic neural cell therapy by grafting human first trimester-derived neural stem/progenitor cells (hfNPCs), to lesioned or control slices. We conclude that human spinal cord tissue slice culture is a suitable complementary platform to study human spinal cord development, injury, and treatment strategies.

\section{Methods}

\section{Human tissue collection}

Human first trimester embryonic/fetal brain stem and spinal cord tissues (5-10.5 weeks postconception (w.)) were collected after elective abortions with maternal oral and written informed consent and following ethical permission from the Regional Human Ethics Committee, Stockholm (lately referred to as Swedish Ethical Review Authority), and the National Board of Health and Welfare, Sweden. The postconceptional age of tissue was determined by examination of anatomical landmarks according to the atlas of normal human development [35]. The tissues were dissected in physiological sodium chloride solution under sterile conditions. Directly thereafter, tissues were cut with a Mcllwain chopper and processed as described below.

\section{Experimental design}

Human spinal cord tissue was collected and ex vivo cross- or longitudinal sections processed for slice culture (in the following text referred to as human organotypic slice culture, hOC) on day 0 . In order to validate our ex vivo slice culture scoring system, we scored the slices in vitro during culture by phase contrast microscopy at 2 DIV, 7 DIV, 14 DIV, and 21 DIV as well as fixed slices at 0 (in situ), 7 DIV, 14 DIV, and 21 DIV, respectively, for histo- and immunohistochemical analysis for comparison, as illustrated in Fig. 1A. We also measured the area of each slice at 7-8 DIV, 14 DIV, and 21 DIV. In order to validate the functionality of the hOC slices, we imaged and measured $\mathrm{Ca}^{2+}$ signaling at 14 and 21 DIV and performed electrophysiological recordings at 7 and 14-15 DIV. With the aim to evaluate acute effects of allogeneic experimental hfNPC therapy in "SCI," we performed slice contusion at $7 \mathrm{DIV}$, and $1 \mathrm{~h}$ afterwards, sham or hfNPC grafting was applied in lesioned or control slices. Slices with and without lesions and grafts were analyzed by immunohistochemistry as well as flow cytometry. For an overview of the design of study, see Fig. 1A.

\section{hfNPC culture}

hfNPCs were initially isolated from human first trimester spinal cord (5-7.5 w.) after consent procedures as described above. The tissues were mechanically homogenized with a Teflon glass homogenizer and cultured as neurospheres as previously described by us [36-40]. A vast majority of the hfNPCs were nestin-positive neural progenitor cells with only about $0.5 \%$ of the cells being Tra-1-60, Tra-1-81, or SSEA-4-positive (all early stem cell markers), with a potential to differentiate into $\beta$ tubulin III- (neuronal marker) and GFAP (glial marker)immunoreactive cells as well as a sparse number of Gal 


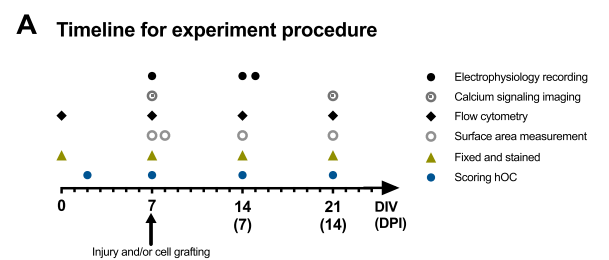

C
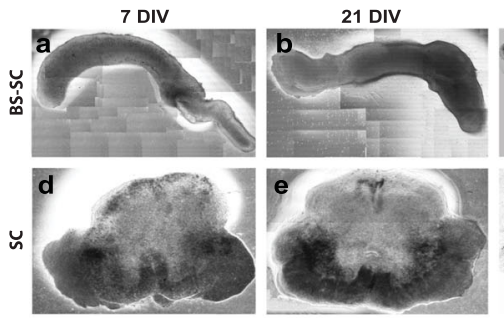

E
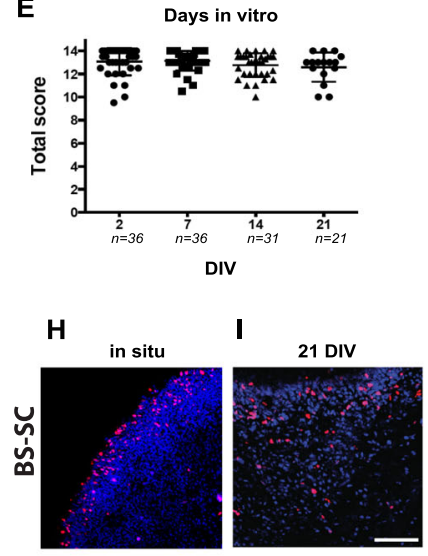

$\mathbf{J}$
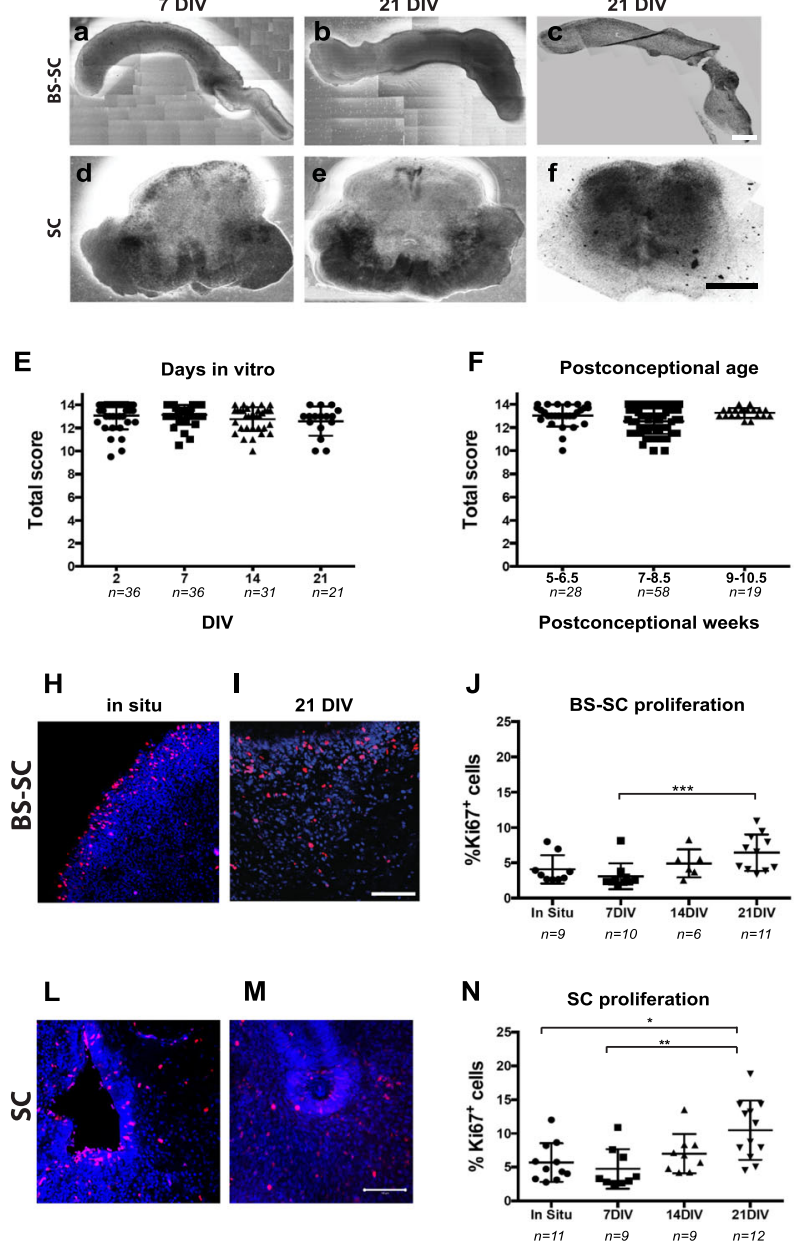

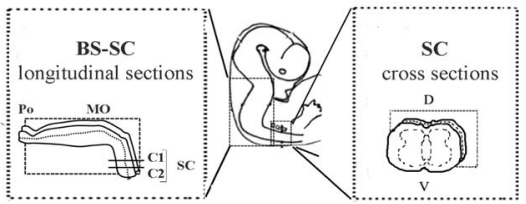

D

in vitro vs cresyl violet $\Delta$ hoc medium
Serum and glu
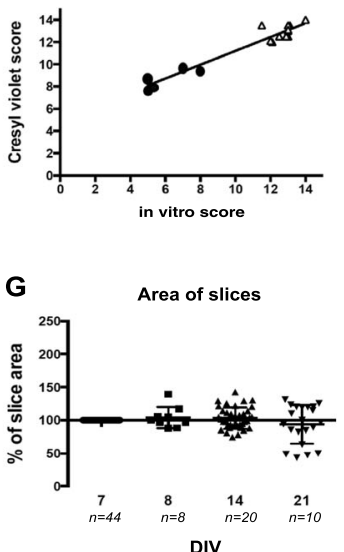

K
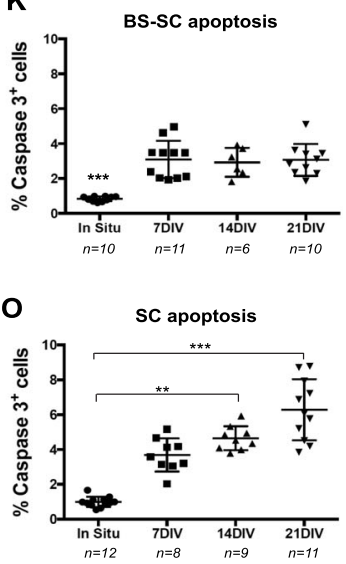

Fig. 1 Timeline and quality of slices during culture. A Schematic timeline for the experimental procedure. B Schematic picture of the longitudinal BS-SC and cross-sectional SC slice cultures. C Appearance of longitudinal BS-SC and cross SC sectional slices at 7 (a, d) and 21 (b, e) DIV. In (c) and (f), Cresyl violet staining at 21 DIV of BS-SC and SC slice cultures, respectively, are shown. D The correlation between the total in vitro hOC score and total postfixation Cresyl violet-based hOC score ( $n=16$ slices from 3 biological cases) is presented. The two total scores were correlated $\left(r_{s}=0.8440\right)$ and linearly distributed $\left(r^{2}=0.9353 ; p<0.0001\right)$. E Total hOC scores of slices cultured under normal conditions at 2, 7, 14, and 21 DIV. F Total hOC score of samples grouped on the basis of their postconceptional week. G The slice area over time in in vitro culture. The area at 7 DIV was considered as 100\%. H, I Ki-67 expression in BS-SC slices in in situ and at 21 DIV, respectively. J, K Flow cytometry quantification of proliferating (J) and apoptotic (K) cells in BS-SC slices. L, M Immunostaining for Ki-67 on SC slices in situ (L) and 21 DIV (M). N, O Flow cytometric quantification of proliferating (N) and apoptotic (O) cells in SC slices. The flow cytometry data is presented as the percentage of positive cells out of total cell number. Values are presented as mean \pm SEM. Bars: $\mathrm{a}-\mathrm{c}=2 \mathrm{~mm}$; $\mathrm{d}-\mathrm{f}=0.5 \mathrm{~mm} . \mathbf{H}, \mathbf{I}, \mathbf{L}, \mathbf{M}=0.1 \mathrm{~mm} .{ }^{*} p<0.05 ;{ }^{* *} p<0.01 ;{ }^{* * *} p<0.001 ;{ }^{* * * *} p<0.0001$. Abbreviations: BS-SC, longitudinal brain stem-spinal cord slices; SC, spinal cord cross-sectional slices; DIV, days in vitro; $n$, number of slices $(\mathbf{E}-\mathbf{G})$ or biological cases $(\mathbf{J}, \mathbf{K}, \mathbf{N}, \mathbf{O})$

C- and O4-positive (oligodendrocyte markers) cells, with low immunogenic potential [36-40].

The cultures were expanded in the absence of antibiotics up to 7 passages. Mycoplasma tests were performed along the course of culture, and no mycoplasma infected cultures were included in the presented data. Tissues were maintained at $37^{\circ} \mathrm{C}, 5 \% \mathrm{CO}_{2}$, and $95 \%$ humidity and the medium was changed three times per week.

\section{Human organotypic culture (hOC)}

The culture method applied here is a modification of the interface method described by Stoppini et al. [13]. 
Human brain stem-spinal cord (BS-SC) longitudinal slices included tissues rostrally from the pontine (PO) flexure and all the way caudally to the second or third cervical segment, (C2-3), while human spinal cord (SC) cross-sections included thoracic or lumbar segments (Fig. 1B). The human tissues were cut with a Mcllwain chopper (Tissue Chopper, Ted Pella, Inc., USA) at $300 \mu \mathrm{m}$ of thickness for longitudinal BS-SC slices or $200 \mu \mathrm{m}$ of thickness for SC cross-sectional slices and thereafter transferred to culture dishes with DMEM medium.

The slices were placed in 6-well plates on a semi-porous membrane (pore size $0.4 \mu \mathrm{m}$, Millipore) pre-treated with poly-D-Lysine and with $1.2 \mathrm{ml}$ of culture medium (DMEM/F12 (1:1) supplemented with glutamax, 25\% inactivated horse serum, $0.65 \%$ glucose, $15 \mathrm{mM}$ Hepes, $1 \%$ penicilin/streptomycin) in each well with the aim to neither cover nor dehydrate the slice [13]. Tissues were maintained at $37^{\circ} \mathrm{C}, 5 \% \mathrm{CO}_{2}$, and $95 \%$ humidity and the medium was changed two to three times per week.

Some control slices were cultured under serum- and glucose-deprivation (DMEM/F12 (1:1) supplemented with glutamax, $15 \mathrm{mM}$ Hepes, $1 \%$ penicillin/streptomycin) when validating our in vitro hOC score as described below.

\section{In vitro evaluation of slices: hOC score}

At 2, 7, 14, and 21 DIV, slice culture appearance was rated under a light inverted phase contrast microscope utilizing a $2.5 \mathrm{x}$ objective. Different parameters of the cross-sectional tissue slices were evaluated, such as the maintenance of regional shape, regional landmarks, tissue slice edge integrity, and others described in Table 1, where each parameter was scored on a scale between 0 and 2 . The hOC score protocol was developed for SC crosssectional slices. The area $(A)$ of the cross-sectional slices was calculated, $A=\pi r^{2}$, where $r$ is the average of the dorso-ventral and the lateral-lateral radius in millimeters.

Same slices were evaluated and scored by three independent observers, first during in vitro culture under phase contrast microscope at 7-8 DIV and 14-15 DIV, and then second after fixation and histochemistry by light microscopy. The intra- and inter-rater variability of the hOC score was calculated. The slices that at 7 DIV had a total score lower than 10 out of maximum 14 points, and thereby presented lost anatomical orientation and/or structural integrity, were excluded from experimental contusion lesion and human allogeneic cell therapy studies.

\section{Immunohistochemistry and histochemistry}

At 0 (in situ tissue slices, not cultured), 7, 14, and 21 DIV, hOC slices were fixed in $4 \%$ paraformaldehyde (PFA) diluted in $0.01 \mathrm{M}$ phosphate-buffered saline (PBS)
Table 1 hOC Score Protocol for Human Spinal Cord (SC) Cross Sections

Score and parameters (the total score is the sum of the respective observed scores, max score 14)

Regional shape of slice (observed shape of tissue slice compared to an in situ SC cross section)

2. Maintained

1. Partly maintained

0. Not maintained

Anatomical organization of slice (Observed presence of the following listed land marks)

Landmarks: A) gray/white matter, B) dorsal septum and/or dorsal funiculi, C) (incipient) ventral median fissure and/or ventral funiculi, $\boldsymbol{D}$ ) dorsal horn, $\boldsymbol{E}$ ) ventral horn, F) central canal/neuroepithelial cell layer/ extra canalicular structures

Organotypic landmarks

2. $\geq 3$ landmarks present, intact and bilateral

1. $\geq 3$ landmarks present but not all intact and/or bilateral

$0 .<3$ landmarks present or none of the landmarks are intact, bilateral

Edges

2. Sharp/even ( $>75 \%$ of total slice edge)

1. Partly sharp/even (25-75\% of total slice edge)

0 . Not sharp/even (sharp edges observed in $<25 \%$ of total slice edge)

"Dark aggregates/dark spots" in tissue slice

2. No/few spots

1. Many (covering $\leq 50 \%$ of slice area (1a scattered/1b aggregates))

0 . Vast number (covering $>50 \%$ of slice area (0a scattered/0b aggregates))

Dispersed cells (cells observed outside edge of tissue slice)

2. No or few (observed outside $<5 \%$ of slice edge)

1. Many (observed outside $5-50 \%$ of slice edge)

0 . Vast number (observed outside $>50 \%$ of slice edge)

\section{Thickness of slice, estimated}

2. Maintained (within $>75 \%$ of total area)

1. Partly maintained (within $25-75 \%$ of total area)

0 . Not maintained (thickness maintained within $<25 \%$ of total area)

Tissue integrity

2. Intact tissue structural integrity (within $>75 \%$ of total slice area)

1. Partly intact tissue structural integrity (within $25-75 \%$ of total slice area)

0 . Not intact tissue structural integrity (structural integrity maintained within $<25 \%$ of total slice area)

\section{TOTAL SCORE:}

Extra observations

\section{Fibers}

2. Multiple observed elongated fibers/fiber network ( $>5$ visible outgrowing fibers)

1. One/few $(\leq 5)$ observed long or short fibers

0 . No outgrowing fibers are observed

Size $(\mathrm{mm})$

Length of slice along dorso-ventral axis

Length of slice along lateral-lateral axis 
for $2 \mathrm{~h}$ at $4{ }^{\circ} \mathrm{C}$. Thereafter, hOCs were processed for whole mount staining, or for staining of individually cryostat-cut sections, $10 \mu \mathrm{m}$.

During both procedures, the specimens were washed by Tris buffer saline $\times 1$ with $0.005 \%$ Tween-100 $\times$ and blocked in blocking solution (0.01 M PBS, $0.1 \%$ Triton $\mathrm{X}-100,4 \%$ bovine serum albumin and $2 \%$ normal goat serum). The primary and secondary antibodies (Suppl. Table 1) were also diluted in the blocking solution. Hoechst 33342 (1:400) was applied as a final step used to label cell nuclei prior to the mounting of glass cover slips with poly vinyl-alcohol $(0.1 \mathrm{mg} / \mathrm{ml})$ in DABCO $(1$, 4-diazabicyclo [2.2.2] octane, $0.03 \mathrm{mg} / \mathrm{ml}$ ). Images were acquired with a confocal microscope utilizing the $20 \mathrm{x}$ or 40x objectives and ZEN 2009 software.

Free-floating tissue slice immunohistochemistry was performed on hOC slices while they were still attached to the culture membrane. All incubations were done at room temperature (RT) and with mild shaking. After a rinse in washing buffer, slices were incubated in blocking solution for $1 \mathrm{~h}$, followed by an overnight incubation with the primary antibodies. After incubation with secondary antibodies ( $2 \mathrm{~h}$ in the dark), specimens were stained with Hoechst and mounted on glass slides.

BS-SC and SC slices were cryopreserved in 30\% sucrose in $0.01 \mathrm{M}$ PBS over night at $4{ }^{\circ} \mathrm{C}$, gently removed from the membrane, transferred to cryomolds, embedded in Tissue Tek-OCT compound, and left over night at $4{ }^{\circ} \mathrm{C}$. The in situ control (non-cultured) BS-SC and SC slices were cryopreserved for $24 \mathrm{~h}$ in $30 \%$ sucrose at $4{ }^{\circ} \mathrm{C}$. Thereafter, the samples were frozen in 2-Methylbutan and stored at $-20^{\circ} \mathrm{C}$ until sectioned at $10 \mu \mathrm{m}$ thickness with a cryostat. Then the cryostat cut sections were heated at $95-100{ }^{\circ} \mathrm{C}$ for $20 \mathrm{~min}$ in sodium citrate buffer $(10 \mathrm{mM})$. Specimens were blocked in blocking solution $1 \mathrm{~h}$ as described above, followed by incubation in primary antibodies, overnight at $4{ }^{\circ} \mathrm{C}$. After rinses, secondary antibodies were added for $2 \mathrm{~h}$ at RT, followed by Hoechst labeling of cell nuclei also as described above.

Cresyl violet staining was performed on cryostat cut sections or whole mount slices. Slices and sections were evaluated at 0 (in situ control slices), 7, 14, and 21 DIV and stained and scored with the same hOC score protocol developed for in vitro analysis during culture (Table 1).

Quantification based on immunohistochemistry was conducted with images that were randomly taken in each condition. $\mathrm{DAPI}^{+}$cells were counted automatically by ImageJ, with the same filter for all sections. Marker and DAPI double-positive cells were considered as marker-positive cells.

\section{Flow cytometry}

BS-SC and SC slices were analyzed by flow cytometry to quantify the percentages of proliferative, apoptotic, glial, and immune cells out of the total tissue slice cell number in normal, injured, and/or grafted hOC groups.

Three organotypic slices from each biological case were pooled to run the analysis. After two washes in PBS, slices were digested in TrypLE with $0.1 \%$ DNase I at $37^{\circ} \mathrm{C}$ for $30 \mathrm{~min}$, and mechanically dissociated into single-cell suspensions. Cells were immunolabeled with the respective antibodies (Suppl. Table. 2) at $4{ }^{\circ} \mathrm{C}$ for 30 min and washed and fixed in Cytofix fixation buffer (BD Biosciences). Cytofix/Cytoperm Fixation/Permeabilization Kit (BD Biosciences) were used for intracellular staining following the manufacturer's instructions. The stained cells were analyzed by flow cytometry with a FACScalibur (Becton and Dickinson) and the percentage of positive cells out of total number of hOC cells analyzed by the software FlowJo (Tree Star, Inc.).

\section{Calcium signaling}

SC hOCs maintained in vitro for 7 or 21 days were bulkand bath-loaded in culture media simultaneously with Oregon Green BAPTA-1 AM (OGBP1-AM) in Pluronic F-127 containing 20\% DMSO. OGBP1-AM (40 mM) of $2 \mu \mathrm{l}$ was added on the surface of the slice and additional OGBP1-AM was added to the medium at a final concentration of $40 \mu \mathrm{M}$. OGBP1-AM-loaded slices were then incubated for $30 \mathrm{~min}$ at $37^{\circ} \mathrm{C}, 5 \% \mathrm{CO}_{2}$. The slices were then rinsed twice in KREBS-Ringer's solution $(119 \mathrm{mM}$ $\mathrm{NaCl}, 2.5 \mathrm{mM} \mathrm{KCl}, 1 \mathrm{mM} \mathrm{NaH} \mathrm{PO}_{4}, 2.5 \mathrm{mM} \mathrm{CaCl}_{2}, 1.3$ $\mathrm{mM} \mathrm{MgCl}, 20 \mathrm{mM}$ HEPES, and $11 \mathrm{mM}$ glucose). Before imaging, a drop of BD Matrigel ${ }^{\mathrm{mm}}$ (BD Biosciences) was added on top of the slices to minimize movement artifacts. The Matrigel was left to solidify by incubating the slices $2 \mathrm{~min}$ at $37^{\circ} \mathrm{C}$. Slices on the culture membranes were imaged in KREBS-Ringer's solution at RT and stimulated with $100 \mu \mathrm{M}$ ATP. Images were acquired at $0.5 \mathrm{~Hz}$ using a Zeiss LSM510 META NLO 2-photon laser scanning microscope equipped with a Ti:Sapphire Chameleon Ultra2 laser (Coherent) tuned at $810 \mathrm{nM}$ using a $\times 40 / 0.8$ water immersion objective (Zeiss).

Cells were manually selected using Fiji [41] and the $\mathrm{Ca}^{2+}$ response was quantified with a custom Python script. For each cell, the baseline signal (F0) was calculated by averaging the integrated intensity measured before ATP stimulation. The $\mathrm{Ca}^{2+}$ response is represented by the ratio between the integrated signal intensity at a specific time point and the baseline. A cell was classified as responder if a peak in signal intensity was above $10 \%$ of the baseline.

\section{Electrophysiology}

Longitudinal and cross-sectional hOCs were transferred to a submerged recording chamber and constantly perfused $(3 \mathrm{ml} / \mathrm{min})$ with oxygenated standard artificial cerebrospinal fluid (aCSF) containing (in $\mathrm{mM}$ ) $130 \mathrm{NaCl}$, 
3.5 KCl, $1.25 \mathrm{NaH}_{2} \mathrm{PO}_{4}, 24 \mathrm{NaHCO}_{3}, 2 \mathrm{CaCl}_{2}, 1 \mathrm{MgCl}_{2}$, and 10 glucose with $\mathrm{pH}$ 7.4. Extracellular recording pipettes were made from borosilicate capillaries and filled with standard aCSF. Field potentials were evoked by a single pulse of $50 \mu$ s duration delivered at $0.03 \mathrm{~Hz}$, and the intensity was maintained in a range between $200 \mu \mathrm{A}$ and $2 \mathrm{~mA}$; a stimulus was delivered using a concentric bipolar stimulating electrode (FHC, ME, USA). The distance between the stimulating electrode and the extracellular recording pipette varied between 500 and $800 \mu \mathrm{m}$ along the rostro-caudal axis in the longitudinal slices and was adjusted to obtain an optimal response clearly separated from the stimulus artifact. Recordings were digitized at $10 \mathrm{kHz}$, stored on a personal computer, and analyzed off-line using pCLAMP 10.

\section{Experimental $\mathrm{SCl}$ and hfNPC therapy}

SCI was performed by utilizing the Horizon Infinity spinal cord impactor (Precision Systems and Instrumentation, LLC, USA) set at 25 kDyn (BS-SC hOC slices, $n=26$; SC hOC slices, $n=223$ ).

First, hfNPCs were labeled overnight by adding CellTracker $^{\text {Tis }}$ Orange CMTMR (5-(and-6)-(((4-Chloromethyl)Benzoyl)Amino) Tetramethylrhodamine (Life Technologies), at a concentration of $2.5 \mu \mathrm{M}$ in the medium and then washed with fresh medium for $1 \mathrm{~h}$. Neurospheres with a diameter range within $250-400 \mu \mathrm{m}$ were collected under a dissection microscope and washed in organotypic culture medium. Thereafter, one to two neurospheres (depending on diameter of neurosphere to graft equivalent cell numbers) were grafted to the injury site (Suppl. Fig. 5A-I) $1 \mathrm{~h}$ postlesion. In addition, we tested hfNPC grafting (again with equivalent procedure as for the contusion SCI) after a mechanical cut of the unilateral dorsal horn (immature dorsal alar plate) of SC cross-sectional slices (Suppl. Fig. 5J-W).

\section{Statistical analyses}

All statistical analyses were performed using Instat 3 and Prism6 (GraphPad Software Inc., USA) for Macintosh computers. Correlation and regression analyses for in vitro and Cresyl violet total hOC score were performed using Spearman's nonparametric correlation $\left(r_{s}\right)$ followed by regression $\left(r^{2}\right)$ analysis. Analysis of possible differences among groups from different postconceptional ages or the groups evaluating neural cell therapy study were performed by the nonparametric KruskalWallis test followed by Dunn's post hoc test. For the $\mathrm{Ca}^{2+}$ signaling data, two-tailored statistical analyses were performed using Mann-Whitney's nonparametric correlation. $P$ values less than 0.05 were considered statistically significant. Results are presented as mean \pm SEM. The number $(n)$ of biological cases and or slices used in each study is indicated in corresponding results and figures.

\section{Results}

First, we established BS-SC and SC hOCs derived from 5 to $10.5 \mathrm{w}$. while evaluating stability, tissue organization, cellular heterogeneity (Fig. 1), and functional viability up to $21 \mathrm{DIV}$. Then, we applied and tested the hOCs as a human ex vivo SCI model and assessed experimental human allogeneic neural cell therapy.

\section{Generation of hOC slices from first trimester human CNS In vitro observations by phase contrast microscopy}

To assess hOC stability and quality, we examined slices under a phase contrast microscope daily up to 21 DIV (Fig. 1C). Both BS-SC and SC hOC slices were relatively well maintained regarding their regional tissue slice shape, edges, anatomical landmarks, and tissue integrity up to 21 DIV (Fig. 1D) with postconceptional ages ranging between 5 and $10.5 \mathrm{w}$. However, there were some exceptions in BS-SC slices, where the tissue integrity of the BS region in older cases (9-10.5 w. group) at 14 DIV and 21 DIV was compromised, slice area increased, gray and white matter areas were difficult to distinguish, edges were uneven, and dispersed cells covered almost all of the BS perimeter (Suppl. Fig. 1). In SC hOCs, the anatomical organization was stage-dependent with postconceptional age of the tissue. Slices derived from 5 to 6.5 w. naturally presented no (5.5 w.; Suppl. Fig. 1D) or few visible (6-6.5 w.; Suppl. Fig. 1E) landmarks such as dorsal/ventral horns and incipient ventral fissure not yet fully developed at initiation of culture, while slices $\geq 7 \mathrm{w}$. (Suppl. Fig. 1 A, C) presented a more developed anatomical organization which was preserved up to 21 DIV.

In almost all hOC slices and cases, after 7 DIV or 14 DIV, neuritic fibers were extending in a network around and away from the tissue slices (Suppl. Fig. 1). The in vitro observations of hOCs by phase contrast microscopy were supported by Cresyl violet staining (Fig. 1C (c, f)).

To test the validity of the hOC score protocol, some slices were cultured under serum- and glucose-deprived condition, which resulted in fewer recognizable land marks and slices became further flattened with uneven edges, and the so-called "dark spots" disappearing (Suppl. Fig. 1 F-G).

\section{hOC score validation}

The slice status was semi-quantitatively evaluated by utilizing a hOC score protocol with a score range of 0 14 (Table 1). The median of absolute differences of each parameter in intra- and inter-observer scores was in the majority of cases 0 . The variation between different observers was not significantly different $(p>0.05)$. To further support the validity of our protocol, we stained a subset of slices with Cresyl violet (slice number $=7$ deriving from 3 biological cases, $n=3$ ) to compare the in vitro hOC score of slices cultivated under normal 
conditions (Fig. 1D, triangle symbols in graph), or in serum- and glucose-deprived conditions (Fig. 1D, black circle symbols in graph). The ex vivo culture and Cresyl violet-based hOC score correlated strongly $\left(r^{2}=0.84\right)$ and presented a linear regression $\left(r^{2}=0.9353 ; p<0.0001\right.$, Fig. 1D), supporting the validity of the hOC score protocol. In this subset of slice cultures, the ones cultured with regular hOC media all got a score value $\geq 10$, while slices cultured under deprived conditions all got a total score $<10$.

\section{Quality of hOC relative to postconceptional age and time in culture}

The total hOC scores recorded for all control (uninjured) spinal cord slices (at 2, 7, 14, and 21 DIV) were stable and ranged between 2, 7, and 14, up to 21 DIV (Fig. 1E). When hOC slices were analyzed on the basis of their weeks postconception, no significant differences were detected among the three stage groups (5-6.5, 78.5, and 9-10.5 w.), even if the older group (9-10.5 w.) appeared more homogeneous (total score range12-14) when compared to the 5-8.5 w. group (total score range 10-14) (Fig. 1F). These observations suggest that the tissue quality of our human slice culture is stable up to 21 DIV, regardless of the initial postconceptional age of the tissue.

At 14 DIV and 21 DIV, the slice area was nonsignificantly different from that of 7 DIV (Fig. 1G). The mean thickness of SC slices postfixation was approximately $120 \mu \mathrm{m}$ including approximately $8-10$ cell layers at 21 DIV.

\section{Proliferation and apoptosis in hOC}

The degree of cell proliferation and apoptosis over time in vitro in hOCs were evaluated respectively, by detecting Ki- $67^{+}$and activated caspase- $3^{+}$cells via immunohistochemistry and flow cytometry between 0 (in situ), 7 , 14, and 21 DIV (Fig. 1H-O and Suppl. Fig. 3).

The Ki- $67^{+}$cells in in situ sections (from 5.5, 8, and $10.5 \mathrm{w}$. cases) were mainly localized in the neuroepithelium around the fourth ventricle (BS-SC longitudinal slices, Fig. $1 \mathrm{H}$ ) or immature central canal (SC slices, Fig. 1L). At $21 \mathrm{DIV}$ in the hOCs, proliferating Ki-67 cells were scattered all over the parenchyma, irrespectively of the developmental stage (Fig. 1I, M).

The number of $\mathrm{Ki}-67^{+}$cells increased over time in culture, as analyzed by flow cytometry. At 21 DIV, the percentage of this proliferating subpopulation was two-fold larger in both BS-SC $(6.4 \pm 2.6 \%)$ and SC $(10.5 \pm 4.4 \%$, compared to that at 7 DIV in BS-SC $(3.1 \pm 1.8 \%$; $p<$ 0.001 ) and SC $(4.7 \pm 2.9 \%) ; p<0.01$ (Fig. 1J, N). When hOCs were compared to in situ slices from the same cases, only SC slices at 21 DIV showed a significant increase of proliferating cells $(5.7 \pm 2.8 \%$ and $10.5 \pm 4.4 \%$, in situ and 21 DIV, respectively, $p<0.05$, Fig. $1 \mathrm{~N})$. When evaluating whether postconceptional age of original tissues affected proliferation in hOC, the $5-6.5 \mathrm{w}$. group presented a higher percentage of $\mathrm{Ki}-67^{+}$cells at $21 \mathrm{DIV}$ (BS-SC, $9.7 \pm 1.1 \%$; SC, $10 \pm 2.5 \%$ ) compared to that at 7 DIV (BS-SC, $2.2 \pm 0.4 \%$; SC, $3.8 \pm 1.8 \%$ ) in both BS-SC $(p<0.01)$ and SC slices $(p<0.05)$ (Suppl. Fig. 2A, B). Moreover, at 21 DIV, the BS-SC slices from 5 to $6.5 \mathrm{w}$. had a significantly higher percentage of proliferating cells compared to the oldest group $(10 \pm 2.5 \%$ and $4.8 \pm$ $2 \%$, respectively; $p<0.05$ ) (Suppl. Fig. 2A).

The size of the caspase- $3^{+}$subpopulation in BS-SC hOCs significantly increased at 7 DIV $(3.1 \pm 1.1 \%), 14$ DIV $(2.9 \pm 0.2 \%)$, and 21 DIV $(3.1 \pm 0.9 \%)(p<0.001$, Fig. $1 \mathrm{~K})$ compared to in situ $(0.8 \pm 0.1 \%)$ BS-SC slices. In SC slices, caspase- $3^{+}$cells significantly increased at 14 DIV $(4.4 \pm 0.1 \% ; p<0.001)$ and 21 DIV $(6.3 \pm 1.7 \% ; p<$ $0.05)$ compared to in situ $(0.9 \pm 0.3 \%)$, while no significant increase was observed at 7 DIV $(4.7 \pm 2.7 \%$, Fig. 1O).

In BS-SC slices, the 5-6.5 w. group presented a significant elevation $(p<0.05)$ in caspase- $3^{+}$cells at 14 DIV $(3.6 \% \pm 0.7 \%)$ and 21 DIV $(3.3 \pm 1.2 \%)$ compared to in situ $(0.9 \pm 0.1 \%)$ (Suppl. Fig. 2C). The apoptosis level was quite stable among the studied postconceptional weeks except for BS-SC at 7 DIV where the older, 9-10.5 w. group showed a significant elevation in caspase $-3^{+}$cells compared to the youngest group $(4.1 \pm 0.8 \%$ and $2.1 \pm$ $0.2 \%$, respectively; $p<0.05$, Suppl. Fig. $2 C$ ).

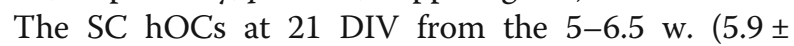
$2.9 \%)$ and $7-8.5$ w. $(5.8 \pm 1.4 \%)$ stage groups showed significant increase $(p<0.05)$ in caspase- $3^{+}$cells compared to the in situ (5-6.5w., $1.1 \pm 0.3 \%$; 7-8.5 w., $0.9 \pm 0.2 \%$ ) (Suppl. Fig. 2D), while no significant differences were detected between different postconceptional stages after the same in vitro culture time (Suppl. Fig. 2D).

All together, these results indicate a relatively stable slice viability with less than $8-9 \%$ of apoptotic cells in the hOCs up to 21 DIV.

\section{Neural cell populations in hOC}

Immunohistochemistry was applied to further evaluate the anatomical organization of hOC slices at 21 DIV to that of in situ CNS tissues of 5.5 w., 8 w., and $10.5 \mathrm{w}$.

After 21 DIV, all BS-SC and SC hOCs irrespective of original postconceptional age presented morphological features similar to in situ tissues from $5.5 \mathrm{w}$. to $10.5 \mathrm{w}$. (Fig. 2).

In both longitudinal in situ tissues (5.5-10.5 w.) and BS-SC slices at 21 DIV, nestin, DCX, and MAP-2 were abundant in most of the parenchyma (Fig. $2 \mathrm{~A}-\mathrm{F}$ ). $\mathrm{NF}^{+}$ fibers were mainly organized in bundles (Fig. 2G, H) while $\mathrm{TH}^{+}$and 5 - $\mathrm{HT}^{+}$immature cell bodies were grouped in clusters in the brain stem nuclei (Fig. 2I-L), 


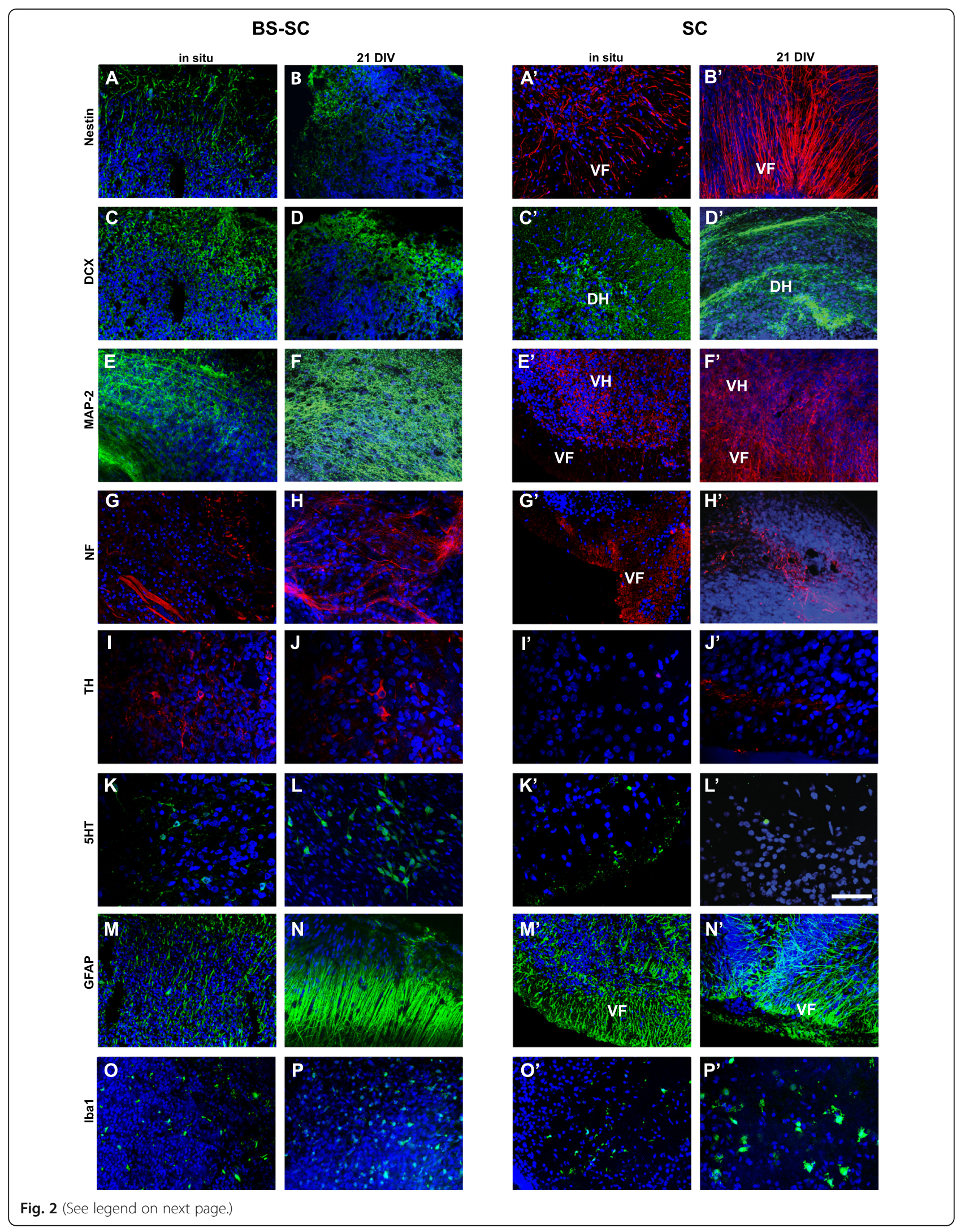


(See figure on previous page.)

Fig. 2 Neural cell populations. Representation of neural populations in BS-SC (A-P) sections and SC ( $\left(\mathbf{A}^{\prime}-\mathbf{P}^{\prime}\right)$ whole slices at in situ (from 8.5 to 10.5

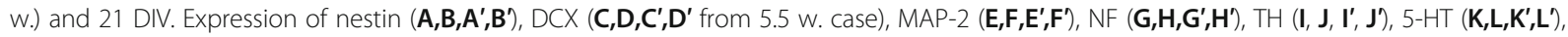

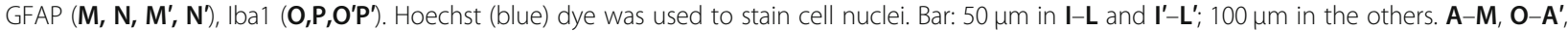
$\mathbf{C}^{\prime}, \mathbf{E}^{\prime}, \mathbf{G}^{\prime}, \mathbf{I}^{\prime}, \mathbf{K}^{\prime}, \mathbf{M}^{\prime}, \mathbf{O}^{\prime}$ : confocal micrograph from $10 \mu \mathrm{m}$ section; $\mathbf{N}^{\prime} \mathbf{B}^{\prime}, \mathbf{D}^{\prime}, \mathbf{F}^{\prime}, \mathbf{H}^{\prime}, \mathbf{J}^{\prime}, \mathbf{L}^{\prime}, \mathbf{N}^{\prime}, \mathbf{P}^{\prime}$ : confocal micrograph from whole slice. Abbreviations: BS-SC, longitudinal brain stem-spinal cord slices; SC, spinal cord cross-sectional slices; VF, ventral funiculi; DH, dorsal horns; VH, ventral horns

and their immunoreactive fibers ran in the white matter tracts of the human cervical spinal cord. In the SC in situ tissues studied from 5.5 to $10.5 \mathrm{w}$. as well as in slices at 21 DIV, nestin ${ }^{+}$cell bodies and fibers were abundantly distributed and aligned all through the tissue slices in both gray and white matter areas (Fig. 2A', B').

However, a few differences in cellular distribution were still detected between the hOCs and in situ tissues of respective postconceptional age. At 21 DIV, BS-SC hOCs presented an increase in MAP-2 and GFAP immunoreactivity (Fig. 2F, N), with hypertrophic $\mathrm{GFAP}^{+}$cells as compared to in situ slices (Fig. 2E, M). In in situ tissues (from $5.5 \mathrm{w}$. to $10 \mathrm{w}$.), MAP- $2^{+}$cells were mainly confined to gray matter areas (Fig. 2E') with fiber bundles running through the white matter, while in hOCs at 21 DIV, MAP-2 was abundant in the whole slice, including the axotomized white matter rim (Fig. 2E', $\mathrm{F}^{\prime}$ ). In in situ tissues, $\mathrm{NF}^{+}$fibers were abundantly detected in the developing white and gray matter, while after $21 \mathrm{DIV}, \mathrm{NF}^{+}$ fibers were mainly observed within the gray matter (Fig. 2G', $\mathrm{H}^{\prime}$ ) most probably due to axotomy during slice preparation. At $21 \mathrm{DIV}$, sparse $\mathrm{TH}^{+}$fibers could be observed in the ventral SC white matter (Fig. 2I', $\mathrm{J}^{\prime}$ ). Fine $5-\mathrm{HT}^{+}$fibers were also discernible along the white matter in in situ tissues (Fig. $2 \mathrm{~K}^{\prime}, \mathrm{L}^{\prime}$ ). $\mathrm{Iba1}^{+}$cells in in situ (from $5.5 \mathrm{w}$. to 10.5 w.) tissues were found sparse but evenly distributed in the tissues (Fig. 2O, $\mathrm{O}^{\prime}$ ), while after 21 DIV, Iba1 ${ }^{+}$cells in the SC slices were large and often distributed on the tissue slice surfaces where the tissue had been exposed to the air-liquid interface (Fig. 2P', air interface side visualized). In in situ SC (5.5-6 w.), DCX was expressed all over the parenchyma, while at $21 \mathrm{DIV}, \mathrm{DCX}^{+}$cells were mainly grouped in clusters in the dorsal horns and along the dorsal white matter (Fig. 2C', D').

In addition, glial cell populations were quantified by flow cytometry as $\mathrm{GFAP}^{+}, \mathrm{CD}_{11 \mathrm{~b}}{ }^{+} \mathrm{CD} 45_{\text {low }}$, and HLA$\mathrm{DR}^{+} / \mathrm{CD} 11 \mathrm{~b}^{+} \mathrm{CD} 45_{\text {low }}$ cells (Fig. 3). In both BS-SC and $\mathrm{SC}$ slices, the number of $\mathrm{GFAP}^{+}$cells (Fig. 3A, F) and $\mathrm{CD} 11 \mathrm{~b}^{+} \mathrm{CD} 45_{\text {low }}$ cells (total microglia; Fig. 3B, G) did not present a statistically significant change over time in culture. In BS-SC slices, the HLA-DR ${ }^{+} / \mathrm{CD} 11 \mathrm{~b}^{+} \mathrm{CD} 45_{\text {low }}$ subpopulation (activated microglia; Fig. $3 \mathrm{C}$ ) was also observed unaffected over time in culture, while in SC slices at $21 \mathrm{DIV}$, the percentage of $\mathrm{HLA}-\mathrm{DR}^{+} / \mathrm{CD} 11 \mathrm{~b}^{+} \mathrm{CD} 45_{\text {low }}$ cells $(10.1 \pm 0.3 \%)$ was significantly higher compared to that at 7 DIV $(6.6 \pm 1.6 \%)$ and in situ $(6.6 \pm 2.7 \%) p<$
0.05, Fig. 3H. For representative flow cytometric dot plot graphs, see Suppl. Fig. 4D-F.

To further evaluate the degree of inflammation in our human slice culture, we performed immunohistochemistry with the proinflammatory marker HLA-DR on slice cultures at 7DIV and 14DIV, respectively. We observed low numbers of HLA-DR ${ }^{+}$cells at these in vitro stages, with no statistically significant difference $(0.8 \%$ at 7 DIV and $0.7 \%$ at 14 DIV) (Suppl. Fig. 4A-C). Altogether, this suggests that the human slice culture model presents (based on the studied markers) relatively stable neuronal subpopulations as well as the degree of inflammation over time in culture, offering opportunity for in vitro human "SCI" study.

\section{Cells of hematopoietic origin}

Despite all the rinsing during the dissection procedures, a small population of hematopoietic-derived cells was observed in the hOC slices. The developmental first trimester stage studied is also the time when microglial cells deriving from the hematopoietic lineage first appear in the central nervous system. As observed by flow cytometry, $0.5 \pm 0.5 \%$ of $\mathrm{CD} 11 \mathrm{~b}^{+} \mathrm{CD} 45^{\text {high }}$ (macrophages)

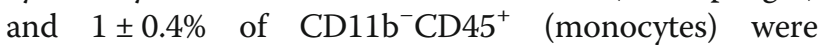
present in the tissue samples (Fig. 3D-J). During culture, despite the increase of both populations in SC slices, the mean population sizes still always represented less than $3 \%$ of the total cell population. By immunohistochemistry, blood vessels were recognized in in situ tissues, but disappeared over time in culture and no laminin signal was detected at 21 DIV in either BS-SC or SC slice cultures (not shown).

\section{Calcium signaling}

To determine if the cells from the SC hOCs were functionally active, we assessed spontaneous $\mathrm{Ca}^{2+}$ activity at 7 DIV and 21 DIV. Spontaneous $\mathrm{Ca}^{2+}$ activity was observed in the cell soma and cell processes both at 7 DIV and 21 DIV (Fig. 4A and Suppl. Video). Noteworthy, the time in culture did not affect the number of responding cells (7 DIV, $8.4 \pm 4.2 \%$; 21 DIV, $5.8 \pm 2.8 \% ; p=0.77$; Fig. $4 \mathrm{~B}), n=4$ slices per condition). ATP is an important regulator of intracellular communication in many pathological conditions such as SCI. Therefore, we tested the ability of these first trimester-derived human neural cells to respond to ATP stimulation. We observed that $100 \mu \mathrm{M}$ ATP was able to elicit cellular $\mathrm{Ca}^{2+}$ responses 


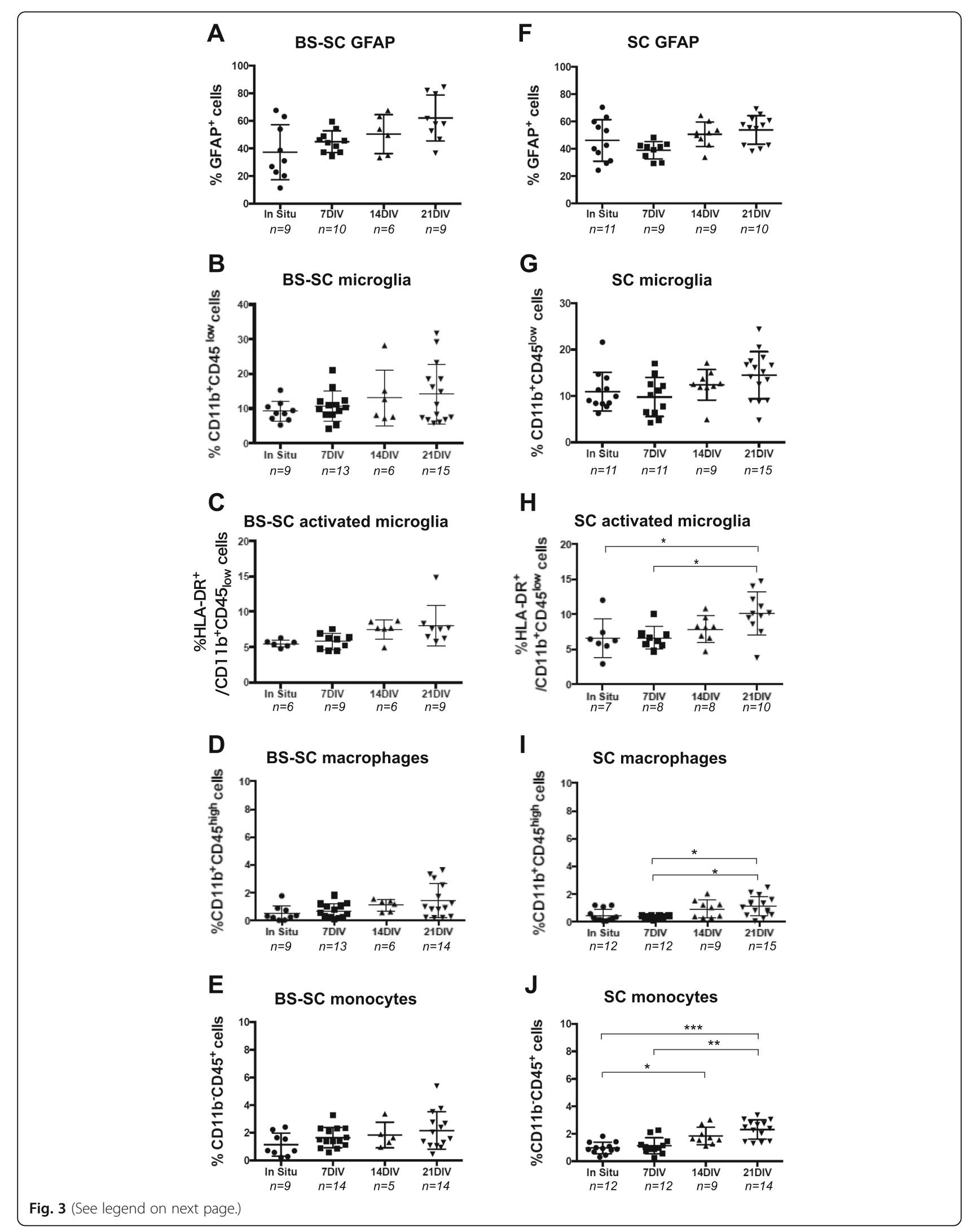


(See figure on previous page.)

Fig. 3 Quantification of glial cells, macrophages and monocytes by flow cytometry. The expression of GFAP (A, F), CD11 b+CD45 low (B, G), HLA$\mathrm{DR}^{+} \mathrm{CD} 11 \mathrm{~b}^{+} \mathrm{CD} 45_{\text {low }}(\mathbf{C}, \mathbf{H}), \mathrm{CD} 11 \mathrm{~b}^{+} \mathrm{CD} 45^{\text {high }}(\mathbf{D}, \mathbf{I})$, and $\mathrm{CD} 11 \mathrm{~b}^{-} \mathrm{CD} 45^{+}(\mathbf{E}, \mathbf{J})$ was assessed by flow cytometry on slices from in situ and 7,14 , and 21 DIV. The degree of positive cells is presented as percentage of immunoreactive cells out of total cell number. Values are presented as mean \pm SEM. ${ }^{*} p<0.05 ;{ }^{* *} p<0.01 ;{ }^{* * *} p<0,001$. Abbreviations: BS-SC, longitudinal brain stem-spinal cord slices; SC, spinal cord cross-sectional slices; DIV, days in vitro; $n$, number of biological cases analyzed per time point

ranging from single transients to oscillatory responses (Fig. 4A, B) without affecting the number of responding cells (7 DIV $15.2 \pm 6.2 \%$, 21DIV $10.8 \pm 6.9 \%, n=4$ ).

\section{Electrophysiological analysis}

To confirm hOC functionality and their ability to transmit neuronal signals, the response to electrical stimulation was assessed in five longitudinal cultures derived from 4.5 w. (two cases) and 6 w., between 7 and 15 DIV.
For this purpose, a recording pipette was placed at a distance between 500 and $800 \mu \mathrm{m}$ from a stimulation electrode along the rostro-caudal axis. Stimulus-evoked potentials were found in all the hOCs tested. Representative superimposed traces, collected after increasing stimulation strength, are shown in Fig. 5; threshold responses were evoked using an intensity of stimulation between 200 and $500 \mu \mathrm{A}$ and maximal responses ranging between 0.5 and $1 \mathrm{mV}$ were obtained with the stimulation

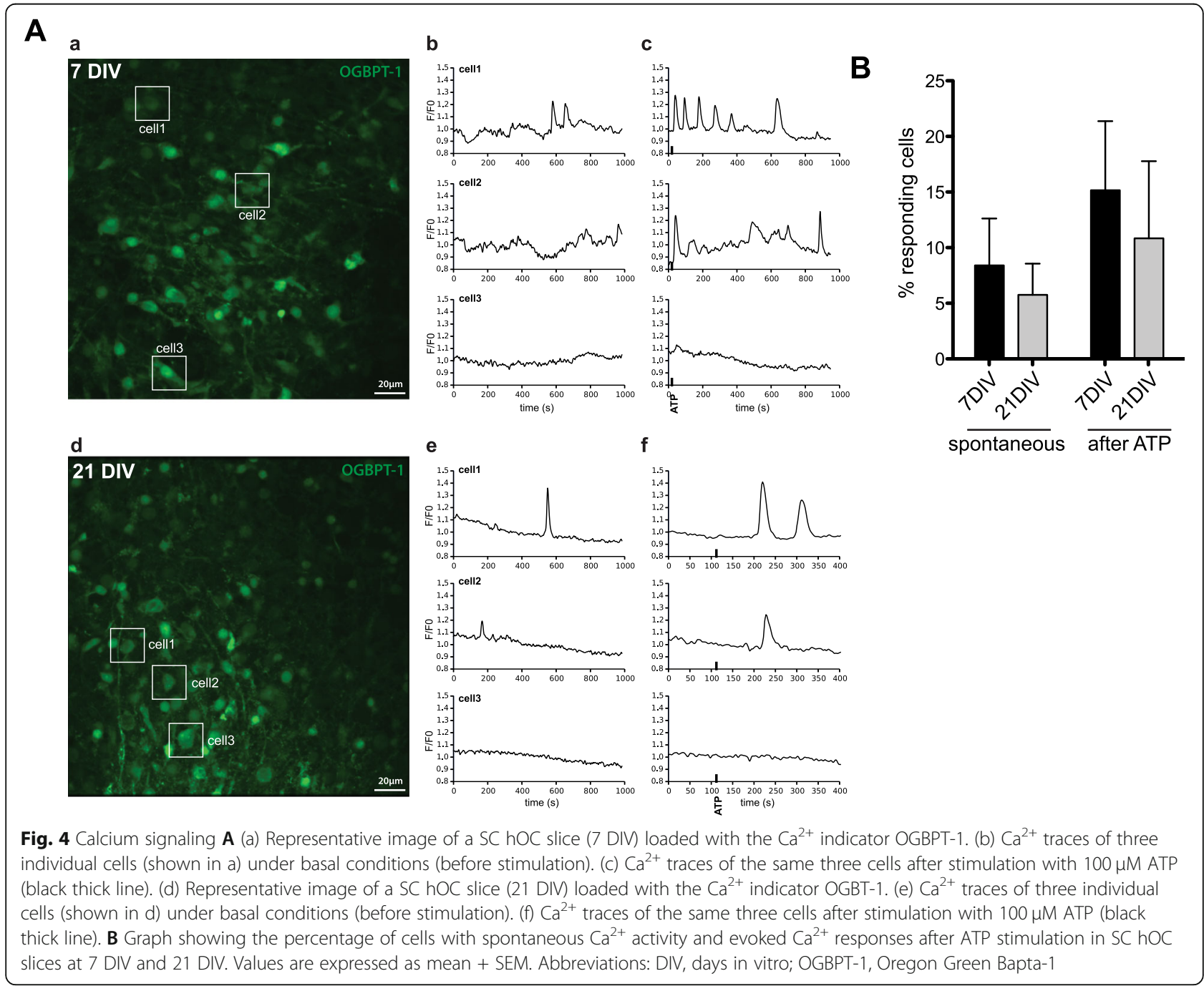




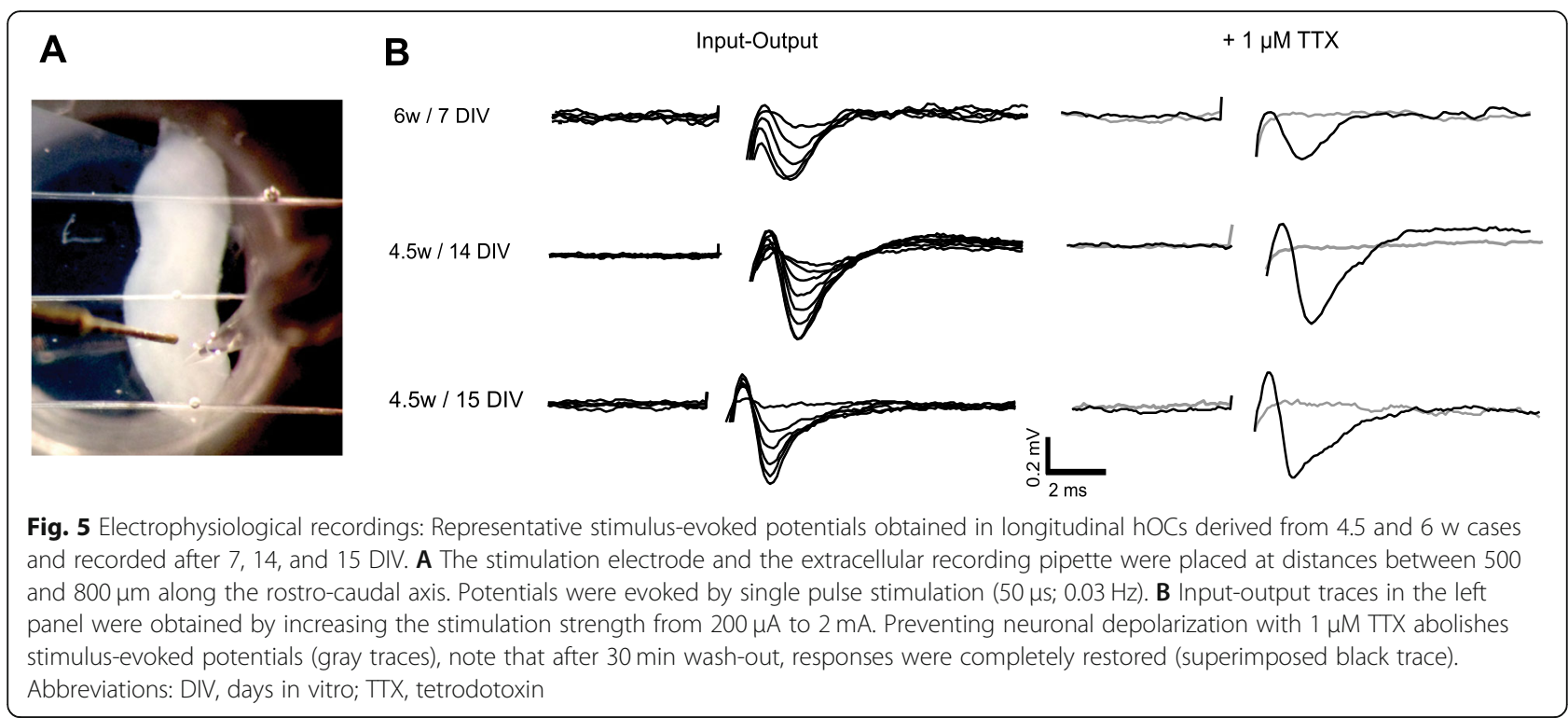

set at 1 to $2 \mathrm{~mA}$. In order to fully confirm the neuronal source of the recorded events, action potentials were blocked using the voltage-gated $\mathrm{Na}^{+}$channel inhibitor, tetrodotoxin (TTX; $1 \mu \mathrm{M}$ ). When present, TTX reversely abolished the stimulus-evoked potentials (Fig. 5).

\section{Human SCI models and allogeneic neural cell grafting}

To experimentally test and utilize the established hOC cross-sectional slices, we mimicked human SCI in the lab in a subset of slices (6-10.5 w.). In addition, experimental human allogeneic neural cell therapy was evaluated utilizing the hOC model system.

\section{Ex vivo model of human $\mathrm{SCl}$}

An experimental contusion injury was performed on SC slices at 7-8 DIV. The slices were maintained up to 14 days postinjury (DPI) while evaluated by the hOC score, slice area (both in vitro under phase contrast microscopy) measured, flow cytometry, histochemistry, and immunohistochemistry.

Prior to injury, the total hOC score was in all cases above 10 (12.3 \pm 0.9$)$, and significantly higher compared to that at $1 \mathrm{DPI}(9.8 \pm 2.2), 7 \mathrm{DPI}(9.8 \pm 2)$, and $14 \mathrm{DPI}$ $(9 \pm 2.7) \quad(p<0.001)$. There were no significant differences between the total hOC scores at 1,7 , and 14 DPI (Fig. 6A).

The slice area was unaffected by the contusion injury per se, as observed by phase contract microscope immediately after the contusion lesion. However, the area significantly increased within $24 \mathrm{~h}$ after injury (Fig. 6B, $p<$ 0.05 ), even if at 7 and 14 DPI a subpopulation of slices (12\% and $35 \%$, at 7 and $14 \mathrm{DPI}$, respectively) presented a smaller area compared to non-injured slices at 7 DIV (Fig. 6B).
The change of the hOC score reflected that the anatomical organization, tissue integrity, and thickness were altered after experimental contusion SCI. Often, a cavity was observed up to at least 14 DPI (Fig. 6C). Immunohistochemistry revealed markedly reduced MAP-2 immunoreactivity in the lesion area and strong GFAP immunoreactivity surrounding the injury site with several round hypertrophic $\mathrm{GFAP}^{+}$cells present after the lesion (Fig. 6D, E).

\section{Allogeneic human neural cell therapy in SCI}

Finally, in order to explore the value of the hOCs in testing potential therapeutic strategies, we grafted "donor" allogeneic hfNPC to "host" slices subjected to contusion SCI and compared them to contusion SCI alone or to sham control slices. The donor hfNPCs in the form of neurospheres were placed on top of the "host" human spinal cord slice at time of grafting. The hfNPCs immediately adhered and within just a few hours the neurosphere was integrated into the "host" slice (see Suppl. Fig. 5).

The outcome was evaluated by flow cytometry at 7 DPI and 14 DPI with and without hfNPC grafts.

At $14 \mathrm{DPI}$, in the injury alone group, both the percentage of active caspase- $3^{+}$cells, $\mathrm{CD}^{+} 8^{+}$and $\mathrm{HLA}-\mathrm{DR}^{+} /$ $\mathrm{CD} 11 \mathrm{~b}^{+} \mathrm{CD} 45_{\text {low }}$ cells significantly increased compared to sham (Fig. 6G, J, and K). In the groups where hfNPCs were grafted to slices with a contusion injury, no significant differences were observed at 14 DPI concerning caspase $-3^{+}$cells and $\mathrm{CD}^{+} 8^{+}$as well as $\mathrm{HLA}-\mathrm{DR}^{+} /$ $\mathrm{CD} 11 \mathrm{~b}^{+} \mathrm{CD} 45_{\text {low }}$ microglia subpopulations compared to the sham group.

The hfNPCs grafted to "normal" sham slices had no perceptible effect on "host slice tissue" at 7 and 14 DPI compared to sham alone (Fig. 6). Also, no significant 
A Total score of contusion injured SC slice
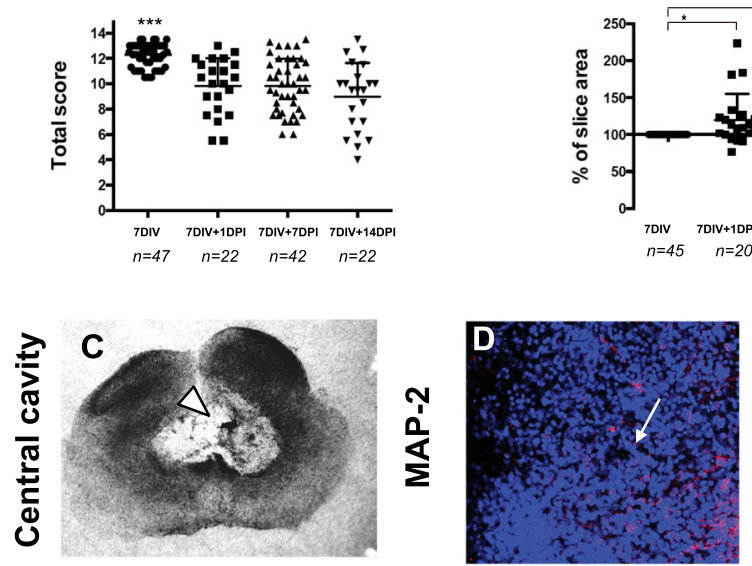

- Sham

- Sham+hNPC

$\triangle \quad$ cSCl

$\mathbf{F}^{\Delta \quad{ }^{C S C I+h N N C}}$

$\mathbf{F}$

SC proliferation

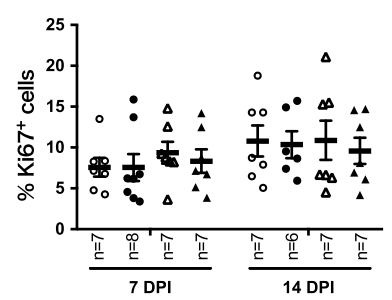

I

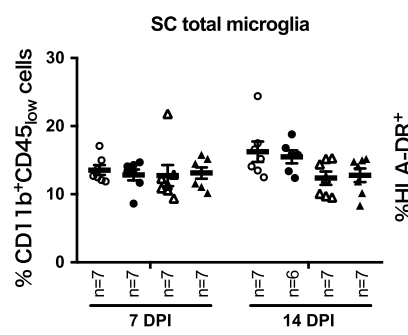

G

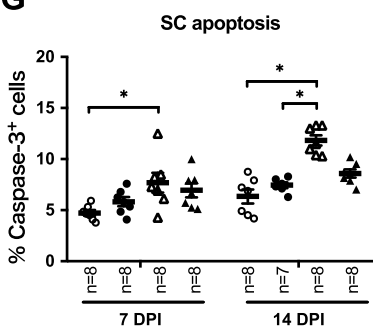

$J$

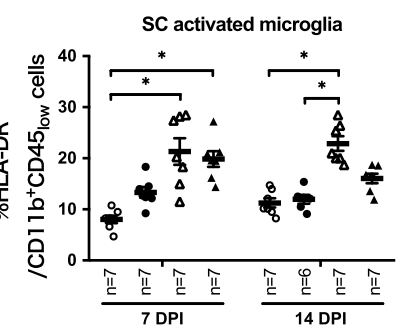

B Area of contusion injured SC slices

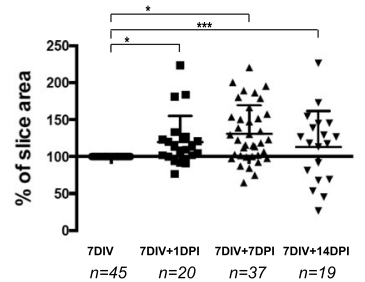

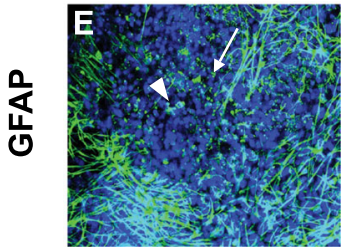

H

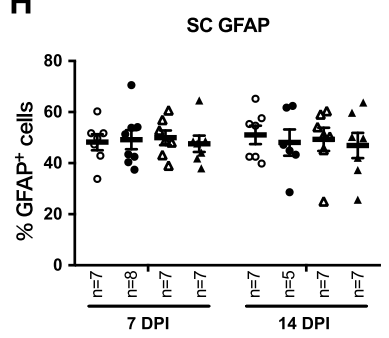

K

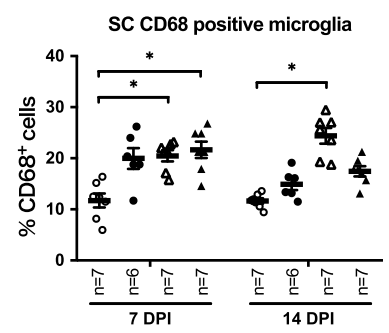

Fig. 6 Human SCI model and experimental allogeneic hfNPC grafting. A Total hOC Score, and $\mathbf{B}$ slice area in SC hOCs before (at 7DIV), 1 (7DIV + 1DPI), 7 (7DIV + 7DPI), and 14 (7DIV + 14DPI) DPI; ${ }^{*} p<0.5,{ }^{* * *} p<0.001$. A, B $n$, number of slices (from in total 8 biological cases). C Appearance of lesion at 14 DPI, phase contrast micrograph with a central cavity, $\mathbf{D}$ expression of MAP-2 in the center of the lesion, and $\mathbf{E}$ GFAP immunoreactivity at injury site. Cell nuclei were stained with Hoechst dye. Arrows point out lesion area. $\mathbf{F}$ Flow cytometer quantification of Ki-67 $7^{+}, \mathbf{G}$ caspase-3 $3^{+}, \mathbf{H} \mathrm{GFAP}^{+}$, I Cd1 1 b ${ }^{+}$CD 45 low, J HLA-DR ${ }^{+} \mathrm{Cd} 11 \mathrm{~b}^{+} \mathrm{CD} 45_{\mathrm{low}}$, and $\mathbf{K}$ CD68 $8^{+}$cells in sham, sham + hfNPC, contusion "SCl," and contusion "SCl" + hfNPC at 7 and 14 DPI. The percentage of immunoreactive cells out of total cell number is presented. Values are presented as mean \pm SEM. ${ }^{*} p<0.05$. Abbreviations: DIV, days in vitro; hfNPC, human fetal neural progenitor cells; DPI, days post injury; $n$, number of biological cases; $\mathrm{CSCl}$, contusion spinal cord injury

difference was observed between 7 DPI and 14 DPI with or without a hfNPC graft just after injury ("SCI" slice contusion) in regard to the percentage of Ki-67,

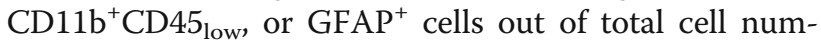
ber (Fig. 6F, H, and I).

These findings suggested that hfNPC grafting offers beneficial effects 14 DPI as observed in this human ex vivo slice culture model.

\section{Discussion}

Reliable models to mimic human conditions for study of development, injury mechanisms, and potential therapies in nervous system lesions, such as SCI, are in great demand to complement experimental in vivo, ex vivo, and in vitro animal models, because of structural and functional species differences [30, 31, 42]. Here, we have developed and evaluated a human ex vivo spinal cord slice 
culture model, allowing us to follow human spinal cord development and SCI pathophysiological mechanisms as well as to test treatment strategies in vitro.

In this paper, the ex vivo human brain stem and spinal cord slice cultures presented remarkably high viability, contained tissue morphology and cellular organization, presence of spontaneous and ATP-induced calcium signaling, and functional neuronal activity in response to electrical stimulation, despite relatively long-term culture up to 21 DIV. We therefore refer to these human ex vivo slice cultures, as organotypic, a term introduced by Reinbold already in 1954 [43, 44].

To our knowledge, there have been only few previously reported attempts to culture human spinal cord tissue in vitro. One ex vivo human spinal cord schwannoma culture [45], one postmortem human spinal cord model derived from adult autopsy tissue [46], and one human fetal spinal cord tissue culture [47]. However, different from these previous reports, the human slice culture method utilized in the present study is an interface-based method (modified from the method by Stoppini et al. [13] and Bonnici and Kapfhammer [48]) that retained relatively intact anatomical structure, local circuitry, glial/neuronal interactions, and viability similar to that reported in cultures of rodent origin [23, 49-51].

In the present paper, a novel and simple hOC score was developed and validated to follow spinal cord crosssectional slice quality over time in culture and after slice injury. The hOC score was also applied prior to randomly assigning slices either to SCI or control group, to support the selection of slices with equivalent quality. Based on the hOC score, human spinal cord slice culture stability and high replicability were observed up to 21 DIV despite varying original postconceptional stages (510.5 w.).

Cell proliferation, as evaluated with the marker Ki-67, was close to double at 21 DIV compared to that in situ and at 7 DIV. With time in culture, a vast spread of Ki$67^{+}$cells from the neuroepithelial cell layer to the surrounding developing parenchyma was observed. This may be due to both the denervation at slice preparation and proliferation and cellular migration in the developing spinal cord. Fernandez-Zafra et al., albeit to a lesser degree, reported a similar finding with proliferation in the neuroepithelial cell layers with subsequent migration in adult rodent spinal cord slice cultures [23].

The level of apoptosis, as revealed by the use of marker caspase-3, increased close to 5 -fold in the crosssectional SC slices and 3-fold in the longitudinal BS-SC slice cultures after 7 DIV, as compared to in situ conditions. The apoptosis in the cross-sectional SC slices increased up to 21 DIV. However, the observed apoptotic cell population was not exceeding $7-8 \%$ of the total cell number despite the complete rostral and caudal transection at the time of slice preparation depleting supraspinal contact in SC slices. This fact is most probably due to the immature status of the originating human tissue having a high proliferative capacity compensating for the initial cell loss (both by necrosis and apoptosis) at the time of slice culture preparation. We, in alignment with Krassiokov et al., observe a relative tissue stabilization at 7 days after initial slice preparation, but are well aware that the preparation per se resulted in denervation with some glial activation (as presented by the GFAP, CD11b flow cytometry) within the cultures.

Immunohistochemistry with antibodies to nestin, DCX, MAP-2, NF, 5-HT, and TH revealed that the neuronal populations that are characteristic of first trimester development were maintained in the human slices.

In the present study, GFAP immunoreactivity was most apparent in the upper and lower periphery of slices. An increase in both signal intensity and enlarged $\mathrm{GFAP}^{+}$cell bodies were revealed by applying immunohistochemistry on the slices. GFAP, the intermediate filament, is widely used as a marker for astrocytes. However, there are also other cells expressing GFAP such as progenitors which are not yet determined as astrocytes [52].

Both flow cytometric data and immunohistochemistry indicated an activated microglial response in the human slice cultures. Microglial cells are of mesodermal origin and initiate migration to the CNS during the first trimester embryonic stage, approximately $5-8$ weeks postconception in human spinal cord [32, 53, 54], which is just the time interval we have studied.

Here we detected $\mathrm{CD} 11 \mathrm{~b}^{+} \mathrm{CD} 45_{\text {low }}$ cell populations to observe overall microglial cells and HLA-DR/ $\mathrm{CD} 11 \mathrm{~b}^{+} \mathrm{CD} 45_{\text {low }}$ to identify activated microglial population, which has been described and applied by others [54]. CD68 is expressed highly in both macrophage and activated microglia but low in resting microglia. In order to further differentiate macrophage and activated microglia, we evaluated also CD11b CD45. Within the CNS, the $\mathrm{CD} 11 \mathrm{~b}^{+} \mathrm{CD} 45_{\text {low }}$ cell population represents CNS microglia, in contrast to $\mathrm{CD} 11 \mathrm{~b}^{+} \mathrm{CD} 45^{\text {high }}$ that is believed to represent the peripherally derived macrophage population $[55,56]$. Resting microglia with ramified morphology also seldomly express MHC class II/ HLA-DR. Instead, HLADR expression is an early indicator of activation. We observed a significant increase in the HLA-DR/ $\mathrm{CD} 11 \mathrm{~b}^{+} \mathrm{CD} 45_{\text {low }}$ macrophage and monocyte populations in the SC slices, but not in the BS-SC slices, over time in culture. This might be due to the earlier migration of the mesodermal originating microglial cells into the human spinal cord compared to the brain stem during this developmental stage [32, 57]. 
Tissue slice culture allows maintenance and development of cellular networks in a microenvironment resembling in vivo condition more closely than cell culture, but with a risk that the structural and functional integrity might be lost over time in culture. In the present study, the calcium signaling and electrophysiological assessment confirmed that a good proportion of the human immature cells remained viable and presented spontaneous and evoked activity during culture, similar to what would be expected in an acutely processed spinal cord slice.

The calcium signaling analysis in the present study, revealed cells exhibiting spontaneous $\mathrm{Ca}^{2+}$ activity and ATP-induced $\mathrm{Ca}^{2+}$ elevations at 7-21 DIV with no significant difference between the two time points. It is tentative to think that most of the $\mathrm{Ca}^{2+}$ response observed post ATP stimulation was due to the neuronal cells that presented spontaneous calcium activity. However, immature neurons (or neuronal progenitors), radial glia, and astrocytes can all exhibit spontaneous $\mathrm{Ca}^{2+}$ activity [58]. Nonexcitable cells such as microglia or endothelial cells can respond to ATP by elevating their cytosolic $\mathrm{Ca}^{2+}$ levels [59]. Therefore, the functional implications of these $\mathrm{Ca}^{2+}$ transients were not elucidated. Future studies aimed at deciphering the role of these $\mathrm{Ca}^{2+}$ responses might benefit using complementary markers, such as sulforhodamine 101, that can help distinguish different cell populations.

For the electrophysiology results, stimulation of the hOCs evoked a robust response with similar thresholds and magnitudes in all slices tested, clearly indicating well-preserved and homogeneous neuronal excitability along all hOCs. Moreover, the evoked response was reversibly blocked by TTX confirming an action-potential dependent neuronal transmission. Even though to our knowledge, the response to electrical stimulation has not been characterized in similar human ex vivo CNS slices preparation, the stimulation protocol and the responses recorded in this study are similar to what has been observed in other spinal cord preparations [60-62].

Both contusion injury and experimental human allogeneic neural cell therapy were applied in the hOCs. The experimental contusion injury significantly increased microglial activation and apoptosis. After grafting hfNPCs to the contusion injured slices, the degree of microglial activation and apoptosis no longer presented a significant difference compared to the sham control group. These findings are in line with SCI rodent models reporting anti-inflammatory [58-62] and neuroprotective effects by in vivo experimental cell therapy [63]. Overall, the human spinal cord slice culture injury model presented similarities of that in in vivo SCI animal models, i.e., loss of neural cells with increased apoptosis, astrocytic, and microglial reaction after contusion injury. However, there are also some clear drawbacks of the slice culture model compared to the in vivo situation, such as lack of an intact blood and lymphatic circulation, no possibility to follow complex functional locomotor behavior and to monitor potential adverse events such as allodynia. Studying in vitro "SCI" in the immature spinal cord, of course also limits the conclusions one may draw to human adult SCI conditions. However, the possibility to perform human study is limited, and adult postmortem tissues are rare with low survival and possibility to follow long term. Therefore, experimental human studies in the present hOC model system based on first trimester stages offer opportunity to additional gain of knowledge to narrow the gap between human and rodent model systems.

Experimental neural stem/progenitor cell therapy has resulted in beneficial effects including a reduction of the post-SCI inflammatory and glial response and host neural cell death in in vivo animal models, as reported by us and others [63-67]. In our previous study, transplanting equivalent donor human spinal cord-derived hfNPCs up to 9 days after SCI [63] resulted in improvement of function (as assessed by the BBB locomotor test) in two biomechanically different animal SCI models. The improvement correlated with increased host rodent spinal cord neuronal survival, indicating a neuroprotective mechanism. The vast majority of donor hfNPCs differentiated into astrocytes months after transplantation with no signs of mechanical allodynia. The therapeutic effect was not significant when a delayed transplantation was applied, again suggesting neuroprotection as the major mechanism of grafted hfNPCs. Cell type(s) offering a protective effect most likely was/were part of the immature NPCs present during the early observed 7-9 days of therapeutic window, since differentiation occurred multiple weeks to months after grafting. The ratios of various differentiated cell types were furthermore not correlated to functional improvement [63]. Therefore, in the present study of the human slice SCI model, we thoroughly evaluated the "host slice" apoptotic and glial cell population rather than the donor cell differentiation potential within this 14 days postgrafting time frame in the slices. Here, we confirm apoptotic and inflammatory characteristics of SCI as well as the potential of experimental cell therapy (previously observed in animal models) in human "SCI" using ex vivo slice cultures with allogeneic cell therapy. This model both allows and calls for further studies on more long-term allogeneic donor cell differentiation and interaction with human spinal cord slices as well as mechanism(s) behind the beneficial effects of human experimental neural cell therapy. 


\section{Conclusions}

In conclusion, we have further developed the human organotypic spinal cord slice culture technique and reported that longitudinal and cross-sectional human tissue slices can be cultured up to 21 DIV with remarkably consistent organotypic structural features and with confirmed viability by $\mathrm{Ca}^{2+}$ signaling and electrophysiological analysis. To experimentally challenge and apply the model, we performed in vitro SC slice contusion lesions and tested human allogeneic neural cell therapy with promising results. We conclude that human spinal cord slice cultures offer a suitable platform, which allows detailed studies of human CNS development and the evaluation of novel treatment strategies for CNS lesion/ "SCI" in vitro with reduced species-specific obstacles. A reliable human CNS slice culture model may narrow the gap between cell suspension culture, in vivo animal models, and human clinical conditions. The human organotypic slice culture is flexible enough for advanced experimental procedures allowing us to test novel treatment strategies in a human-specific setting in parallel to cell culture and in vivo animal models prior to clinical application.

\section{Supplementary information}

Supplementary information accompanies this paper at https://doi.org/10. 1186/s13287-020-01771-y.

Additional file 1: Supplementary video.mp4: This is a 20-second video of the calsium imaging experiment, where at the 12th second, ATP was applied.

Additional file 2 : Supplementary Table 1. Antibodies used in immunohistochemistry. Supplementary Table 2: Antibodies used in flow cytometry. Information of the antibodies used in immunohistochemistry and flow cytometry.

Additional files 3 : Supplementary Figure 1. Phase contrast images for hOC. (A) A Representative BS-SC longitudinal slice deriving from 6$8.5 \mathrm{~W}$. and (B) 9-10.5 W., both at 21 DIV. In cases $<8.5 \mathrm{~W}$., tissue architecture of BS and SC were preserved over time in culture. However, in older cases (>8.5W.) BS partly lost tissue integrity and tissue thickness was reduced to few cell layers, edges were uneven, and dark spots disappeared from BS as seen in (B). Arrows: dark spots; arrowheads: dark aggregates. (C) A representative SC cross sectional slice at 21 DIV, deriving from 7.5-8w. Arrows: dark spots; arrowhead: dark aggregates. (D) A SC slice from $5.5 \mathrm{~W}$. at 21 DIV. Tissue maintained its appearance but at this stage studied landmarks were not fully developed. (E) SC slice deriving from $6 w$ at 21 DIV. Fibers appeared from 7 DIV and they grew creating a network in culture as seen in $(D, E)$. (F) In vitro phase contrast micrograph and (G) Cresyl violet stained hOC SC slices cultured under serum and glucose deprivation for one week. The in vitro slices lost tissue integrity, edges were uneven and was becoming very thin. Bar=0.6 mm. Abbreviations: PO, pons; MO, medulla oblongata; SC, spinal cord; WM: white matter; DF, dorsal funiculi and or dorsal septum; VF, ventral median fissure and or ventral funiculi; $\mathrm{DH}$, dorsal horns or alar plate; $\mathrm{VH}$, ventral horns or basal plate; CC, central canal and or extra canalicula. Supplementary Figure $\mathbf{2}$. Flow cytometric quantification of proliferation, apoptosis, glial cells, microglia on BS-SC and SC slices. Flow cytometric quantification of proliferation (A, B), apoptosis (C, D) and GFAP expression (E, $F$ ) and $C D 11 b^{+} C D 45_{\text {low }}$ expressing cells $(G, H)$ in BS-SC (A, $C, E, G)$ and $S C(B, D, F, H)$ slices cultures, grouped depending on original weeks post conception. (A, B) proliferation increased significantly from
7DIV to that after 21 DIV in slices derived from 5-6.5 w. in both BS-SC (A $p<0.01)$ and SC $(B ; p<0.05)$ slice cultures. At 21 DIV, BS-SC slices derived from $5-6.5 \mathrm{w}$. presented double the percentage of proliferating cells compared to that at $9-10.5 \mathrm{~W}$. $(A ; p<0.05)$. (C, D) In the slices, the amount of apoptotic cells was relatively stable during cultures from 7DIV to 21 DIV, while the percentages of caspase- $3^{+}$cells at 14 and 21 DIV were often significantly higher compared to that in situ $(p<0.05)$. At 7 DIV the proportion of apoptotic cells was higher in 9-10.5w. compared to $5-6.5 \mathrm{w}$. $(p<0.05)$. ( $E, F)$ No significant differences were detected by flow cytometry in the percentage of $\mathrm{GFAP}^{+}$cells among groups at same DIV or over time. Values are presented as mean \pm SEM. ${ }^{*} p<0.05 ;{ }^{* *} p<0.01$.

Supplementary Figure 3. Immunostaining of proliferating and apoptotic cells in BS-SC and SC slices. (A-L) Representative images of Ki-67 (red), caspase-3 (green) and DAPI (blue) immunofluorescent staining on SC (A, C, D, G, H and K) and BS-SC (B, E, F, I, J and L) slices of different time points (in situ, 7 DIV, 14 DIV and 21 DIV). For the in situ and 21 DIV images of Ki-67, please see Fig. 1. Supplementary Figure 4. HLA-DR quantification and representative dot plots of the flow cytometric analysis. (A-B) Representative images of HLA-DR immunofluorescent staining of BS-SC slices of 7 DIV (A) and 14 DIV (B). (C) Quantification of HLA-DR ${ }^{+}$ cells. The image analysis was based on BS-BC slices 7 DIV and 14 DIV (3-4 sections per condition). Images were randomly taken in both conditions. $\mathrm{DAPI}^{+}$cells were counted automatically by ImageJ, with the same filter setting for all sections. HLA-DR ${ }^{+} D A P{ }^{+}$cells were considered as HLA-DR ${ }^{+}$ cells. Values are presented as mean \pm SEM. Bars $=0.1 \mathrm{~mm}$. (D-E) Representative dot plots of the flow cytometric analysis of glial cell populations. (F) Representative dot plots over the hematopoietic cell populations, macrophages and monocytes. Gating is set from the negative isotype controls. Gating strategy: (Da, Db) microglia, CD11b / CD45low; (Da, Db, $\mathrm{Dc}$ ) activated microglia, $\mathrm{CD} 11 \mathrm{~b}^{+} / \mathrm{CD} 45_{\text {low }} / \mathrm{HLA}^{-D R^{+}}$; (Fa, Fb) macrophages, $\mathrm{CD} 11 \mathrm{~b}^{+} / \mathrm{CD} 45^{\text {high }}$; (Fa, Fb) monocytes, CD11b-/CD45 ${ }^{+}$cells. Abbreviations: Iso, mouse IgG isotype control for the respective fluorochromes. Supplementary Figure 5: Phase contrast images of contusion/cut SCl with hfNPC grafts. Data description please see respective figure legends. (A-I) "Donor" allogeneic hfNPCs grafted to "host" slices (G-I) subjected to contusion $\mathrm{SCl}$ and compared to contusion $\mathrm{SCl}$ alone (D-F) or to sham control slices (A-C). (J-W) GFP-hfNPC graft in spinal cord slices. After culture for 9DIV, a mechanical cut in the dorso-lateral spinal cord was performed. 1 hour later, GFP-hfNPCs were grafted at the injury site. Images taken with phase contrast and/or fluorescence microscope at $1 \mathrm{~h}, 3$ or 7 days postinjury. J-M) sham control; N-Q) cut SCl; R-U) cut SCl+ GFP-hfNP(s. V and W) represent green GFP-hfNPC grafted in the slices imaged in $T$ and $U$ with increased magnification. Bar: a-l) $1 \mathrm{~mm} ; \mathrm{m}-\mathrm{n}$ ) $0.5 \mathrm{~mm}$. Size of slices is presented in $\mathrm{mm}$. Score represents the total hOC Score.

\section{Abbreviations}

aCSF: Artificial cerebrospinal fluid; BS-SC: Brain stem-spinal cord; CNS: Central nervous system; DIV: Days in vitro; DPI: Days postinjury; hOC: Human organotypic culture; hfNPC: Human first trimester-derived neural stem/ progenitor cell; PBS: Phosphate-buffered saline; PFA: Paraformaldehyde; PO: Pontine; RT: Room temperature; SC: Spinal cord; SCl: Spinal cord injury; TTX: Tetrodotoxin; w.: Weeks postconception

\section{Acknowledgements}

We wish to thank Eva-Britt Samuelsson for the assistance with human hfNPC cultures (Department of Neurobiology, Care Sciences and Society, Karolinska Institutet), Biomedicine master student Johan Lundberg for tissue slice area measurements, and Prof Åke Seiger for valuable comments on the manuscript.

\section{Authors' contributions}

C.L. has performed human ex vivo spinal cord slice culture and has participated in the data collection, compilation, analysis, and writing of the manuscript. C.C. has participated in conceiving the idea and overall analysis, developed and performed human ex vivo spinal cord slice culture; performed data collection, compilation, and analysis; and drafted the paper. T.F. has performed and analyzed all calcium signaling experiments. J.L. has performed and analyzed flow cytometry data. X.L. has participated in imaging analysis and graphical presentation and provided intellectual input during the paper resubmission process. Å.E-N. has participated in the analysis 
and compilation of flow cytometry data. E.V. has performed and analyzed all electrophysiology data. S.C. has participated in performing and analyzing the calcium signaling experiments. L.H. has performed and analyzed human ex vivo spinal cord slice culture and immunohistochemical analysis. M.L. has conceived and designed the electrophysiology experiments. P.U. has conceived and designed the calcium signaling experiments. E.Å. has conceived the idea, designed the analysis of the studies, written a significant part of the paper and is corresponding author. The authors read and approved the final manuscript.

\section{Funding}

This work was supported by grants from China Scholarship Council, EU Marie Curie IEF postdoctoral fellowship, Becas Talentia, ALF funding, Stockholm County Council, Neuroförbundet, Vetenskapsrådet, Hjärnfonden, and Karolinska Institutet Funds.

Open access funding was provided by Karolinska Institutet.

\section{Availability of data and materials}

All data generated or analyzed during this study are included in this published article and its supplementary information files.

\section{Ethics approval and consent to participate}

Human first trimester brain stem and spinal cord tissues (5-10.5 weeks postconception $(\mathrm{w})$.$) were collected after elective abortions after maternal$ oral and written informed consent and following ethical permission from the Regional Human Ethics Committee, Stockholm/Swedish Ethical Review Authority.

\section{Consent for publication}

Not applicable.

\section{Competing interests}

The authors declare no conflict of interests.

\section{Author details}

${ }^{1}$ Department of Neurobiology, Care Sciences and Society, Div. of Neurogeriatrics, Karolinska Institutet, Stockholm, Sweden. ${ }^{2}$ Department of Neurology and Laboratory of Neuroscience, Università degli Studi diMilan, Milan, Italy. ${ }^{3}$ Division of Molecular Neurobiology, Departmentof Medical Biochemistry and Biophysics, Karolinska Institutet, Stockholm, Sweden. ${ }^{4}$ Department of Neurology, Shengjing Hospital of China Medical University, Shenyang, People's Republic of China. ${ }^{5}$ Department of Clinical Science, Intervention and Technology, Div. of Obstetrics and Gynecology, Karolinska Institutet, Stockholm, Sweden. ${ }^{6}$ The R\&D Unit, Stockholms Sjukhem, Stockholm, Sweden.

Received: 27 February 2020 Revised: 18 May 2020 Accepted: 12 June 2020 Published online: 29 July 2020

\section{References}

1. Gensel JC, Donnelly DJ, Popovich PG. Spinal cord injury therapies in humans: an overview of current clinical trials and their potential effects on intrinsic CNS macrophages. Expert Opin Ther Targets. 2011;15(4):505-18.

2. Ahuja CS, Fehlings M. Concise review: bridging the gap: novel neuroregenerative and neuroprotective strategies in spinal cord injury. Stem Cells Transl Med. 2016;5(7):914-24.

3. Badner A, Siddiqui AM, Fehlings M. Spinal cord injuries: how could cell therapy help? 2017.

4. Filli L, Schwab ME. The rocky road to translation in spinal cord repair. Ann Neurol. 2012;72(4):491-501.

5. Karimi-Abdolrezaee S, Eftekharpour E. Stem cells and spinal cord injury repair. Adv Exp Med Biol. 2012;760:53-73.

6. De Feo D, Merlini A, Laterza C, Martino G. Neural stem cell transplantation in central nervous system disorders: from cell replacement to neuroprotection. Curr Opin Neurol. 2012;25(3):322-33.

7. Rosenzweig ES, Brock JH, Lu P, Kumamaru H, Salegio EA, Kadoya K, et al. Restorative effects of human neural stem cell grafts on the primate spinal cord. Nat Med. 2018;24(4):484-90

8. Garbossa D, Boido M, Fontanella M, Fronda C, Ducati A, Vercelli A. Recent therapeutic strategies for spinal cord injury treatment: possible role of stem cells. Neurosurg Rev. 2012;35(3):293-311.
9. Ronaghi M, Erceg S, Moreno-Manzano V, Stojkovic M. Challenges of stem cell therapy for spinal cord injury: human embryonic stem cells, endogenous neural stem cells, or induced pluripotent stem cells? Stem cells (Dayton). 2010;28(1):93-9.

10. Chapman AR, Scala CC. Evaluating the first-in-human clinical trial of a human embryonic stem cell-based therapy. Kennedy Inst Ethics J. 2012; 22(3):243-61.

11. Curtis E, Martin JR, Gabel B, Sidhu N, Rzesiewicz TK, Mandeville R, et al. A first-in-human, phase i study of neural stem cell transplantation for chronic spinal cord injury. Cell Stem Cell. 2018;22(6):941-50.e6.

12. Sundstrom L. OrganDots -- an organotypic 3D tissue culture platform for drug development. Expert Opin Drug Discov. 2012;7(6):525-34.

13. Stoppini L, Buchs PA, Muller D. A simple method for organotypic cultures of nervous tissue. J Neurosci Methods. 1991;37(2):173-82.

14. Gahwiler BH. Organotypic monolayer cultures of nervous tissue. J Neurosci Methods. 1981;4(4):329-42.

15. Patar A, Dockery P, McMahon S, Howard L. Ex vivo rat transected spinal cord slices as a model to assess lentiviral vector delivery of neurotrophin-3 and short hairpin RNA against NG2. Biology. 2020;9(3):54. https://doi.org/10. 3390/biology9030054

16. Griffin JM, Fackelmeier B, Clemett CA, Fong DM, Mouravlev A, Young D, et al. Astrocyte-selective AAV-ADAMTS4 gene therapy combined with hindlimb rehabilitation promotes functional recovery after spinal cord injury. Exp Neurol. 2020;327:113232

17. Pandamooz S, Salehi MS, Nabiuni M, Dargahi L, Pourghasem M. Evaluation of epidermal neural crest stem cells in organotypic spinal cord slice culture platform. Folia Biol. 2016;62(6):263-7.

18. Kim HM, Lee HJ, Lee MY, Kim SU, Kim BG. Organotypic spinal cord slice culture to study neural stem/progenitor cell microenvironment in the injured spinal cord. Exp Neurobiol. 2010;19(2):106-13.

19. Park H-W, Lim M-J, Jung H, Lee S-P, Paik K-S, Chang M-S. Human mesenchymal stem cell-derived Schwann cell-like cells exhibit neurotrophic effects, via distinct growth factor production, in a model of spinal cord injury. Glia. 2010;58(9):1118-32.

20. Cho Y, Shi R, Borgens RB. Chitosan produces potent neuroprotection and physiological recovery following traumatic spinal cord injury. J Exp Biol. 2010;213(Pt 9):1513-20.

21. Lossi L, Alasia S, Salio C, Merighi A. Cell death and proliferation in acute slices and organotypic cultures of mammalian CNS. Prog Neurobiol. 2009; 88(4):221-45.

22. Kuzhandaivel A, Nistri A, Mazzone GL, Mladinic M. Molecular mechanisms underlying cell death in spinal networks in relation to locomotor activity after acute injury in vitro. Front Cell Neurosci. 2011;5:9.

23. Fernandez-Zafra T, Codeluppi S, Uhlen P. An ex vivo spinal cord injury model to study ependymal cells in adult mouse tissue. Exp Cell Res. 2017; 357(2):236-42.

24. Boomkamp SD, Riehle MO, Wood J, Olson MF, Barnett SC. The development of a rat in vitro model of spinal cord injury demonstrating the additive effects of rho and ROCK inhibitors on neurite outgrowth and myelination. Glia. 2012;60(3):441-56.

25. Abu-Rub M, McMahon S, Zeugolis DI, Windebank A, Pandit A. Spinal cord injury in vitro: modelling axon growth inhibition. Drug Discov Today. 2010; 15(11-12):436-43.

26. Schizas N, Rojas R, Kootala S, Andersson B, Pettersson J, Hilborn J, et al. Hyaluronic acid-based hydrogel enhances neuronal survival in spinal cord slice cultures from postnatal mice. J Biomater Appl. 2014;28(6):825-36.

27. Labombarda F, Ghoumari AM, Liere P, De Nicola AF, Schumacher M, Guennoun R. Neuroprotection by steroids after neurotrauma in organotypic spinal cord cultures: a key role for progesterone receptors and steroidal modulators of GABA(a) receptors. Neuropharmacology. 2013;71:46-55.

28. Krassioukov AV, Ackery A, Schwartz G, Adamchik Y, Liu Y, Fehlings MG. An in vitro model of neurotrauma in organotypic spinal cord cultures from adult mice. Brain Res Brain Res Protoc. 2002;10(2):60-8.

29. Esposito E, Paterniti I, Meli R, Bramanti P, Cuzzocrea S. GW0742, a highaffinity PPAR-delta agonist, mediates protection in an organotypic model of spinal cord damage. Spine. 2012;37(2):E73-8.

30. Oberheim NA, Wang X, Goldman S, Nedergaard M. Astrocytic complexity distinguishes the human brain. Trends Neurosci. 2006;29(10):547-53.

31. Oberheim NA, Takano T, Han X, He W, Lin JHC, Wang F, et al. Uniquely hominid features of adult human astrocytes. J Neurosci. 2009;29(10): 3276-87. 
32. Rezaie P, Male D. Colonisation of the developing human brain and spinal cord by microglia: a review. Microsc Res Tech. 1999;45(6):359-82.

33. Courtine G, Bunge MB, Fawcett JW, Grossman RG, Kaas JH, Lemon R, et al. Can experiments in nonhuman primates expedite the translation of treatments for spinal cord injury in humans? Nat Med. 2007;13(5):561-6.

34. Filipp ME, Travis BJ, Henry SS, Idzikowski EC, Magnuson SA, Loh MY, et al. Differences in neuroplasticity after spinal cord injury in varying animal models and humans. Neural Regen Res. 2019;14(1):7-19.

35. England MA. Colour atlas of life before birth: normal fetal development: Chicago. Year Book Medical Publishers; 1990.

36. Akesson E, Piao JH, Samuelsson EB, Holmberg L, Kjaeldgaard A, Falci S, et al. Long-term culture and neuronal survival after intraspinal transplantation of human spinal cord-derived neurospheres. Physiol Behav. 2007;92(1-2):60-6.

37. Piao JH, Odeberg J, Samuelsson EB, Kjaeldgaard A, Falci S, Seiger A, et al. Cellular composition of long-term human spinal cord- and forebrainderived neurosphere cultures. J Neurosci Res. 2006;84(3):471-82.

38. Akesson E, Wolmer-Solberg N, Cederarv M, Falci S, Odeberg J. Human neural stem cells and astrocytes, but not neurons, suppress an allogeneic lymphocyte response. Stem Cell Res. 2009;2(1):56-67.

39. Odeberg J, Piao JH, Samuelsson EB, Falci S, Akesson E. Low immunogenicity of in vitro-expanded human neural cells despite high MHC expression. J Neuroimmunol. 2005;161(1-2):1-11.

40. Liu J, Gotherstrom C, Forsberg M, Samuelsson EB, Wu J, Calzarossa C, et al. Human neural stem/progenitor cells derived from embryonic stem cells and fetal nervous system present differences in immunogenicity and immunomodulatory potentials in vitro. Stem Cell Res. 2013;10(3):325-37.

41. Schindelin J, Arganda-Carreras I, Frise E, Kaynig V, Longair M, Pietzsch T, et al. Fiji: an open-source platform for biological-image analysis. Nat Methods. 2012;9(7):676-82.

42. Xu X, Stoyanova El, Lemiesz AE, Xing J, Mash DC, Heintz N. Species and celltype properties of classically defined human and rodent neurons and glia. eLife. 2018;7:e37551.

43. Reinbold R. Organotypic differentiation of the eye of the chick embryo in vitro. C R Seances Soc Biol Fil. 1954;148(15-18):1493-5.

44. Humpel C. Organotypic brain slice cultures: a review. Neuroscience. 2015; 305:86-98.

45. Lyser KM. Electron-microscopic observations of a human schwannoma in organotypic culture. Oncology. 1975;31(3-4):244-53.

46. Jeong DK, Taghavi CE, Song KJ, Lee KB, Kang HW. Organotypic human spinal cord slice culture as an alternative to direct transplantation of human bone marrow precursor cells for treating spinal cord injury. World Neurosurg. 2011;75(3-4):533-9.

47. Ducray AD, Qualls R, Schlattner U, Andres RH, Dreher E, Seiler RW, et al. Creatine promotes the GABAergic phenotype in human fetal spinal cord cultures. Brain Res. 2007;1137:50-7.

48. Bonnici B, Kapfhammer JP. Spontaneous regeneration of intrinsic spinal cord axons in a novel spinal cord slice culture model. Eur J Neurosci. 2008; 27(10):2483-92.

49. Gerardo-Nava J, Hodde D, Katona I, Bozkurt A, Grehl T, Steinbusch HW, et al. Spinal cord organotypic slice cultures for the study of regenerating motor axon interactions with 3D scaffolds. Biomaterials. 2014;35(14):4288-96.

50. Sekizar S, Williams A. Ex vivo slice cultures to study myelination, demyelination, and remyelination in mouse brain and spinal cord. Methods Mol Biol. 1936;2019:169-83.

51. Pandamooz S, Salehi MS, Zibaii MI, Safari A, Nabiuni M, Ahmadiani A, et al. Modeling traumatic injury in organotypic spinal cord slice culture obtained from adult rat. Tissue Cell. 2019;56:90-7.

52. Maslov AY, Barone TA, Plunkett RJ, Pruitt SC. Neural stem cell detection, characterization, and age-related changes in the subventricular zone of mice. J Neurosci. 2004;24(7):1726-33.

53. Geny C, Naimi-Sadaoui S, Belkadi AEM, Jeny R, Kammoun M, Peschanski M. Microglial chimaerism in human xenografts to the rat brain. Brain Res Bull. 1995;38(4):383-91.

54. Billiards SS, Haynes RL, Folkerth RD, Trachtenberg FL, Liu LG, Volpe JJ, et al. Development of microglia in the cerebral white matter of the human fetus and infant. J Comp Neurol. 2006;497(2):199-208.

55. Crotti A, Ransohoff RM. Microglial physiology and pathophysiology: insights from genome-wide transcriptional profiling. Immunity. 2016;44(3):505-15.

56. Rangaraju S, Raza SA, Li NX, Betarbet R, Dammer EB, Duong D, et al. Differential phagocytic properties of CD45(low) microglia and CD45(high) brain mononuclear phagocytes-activation and age-related effects. Front Immunol. 2018;9:405.

57. Ginhoux F, Prinz M. Origin of microglia: current concepts and past controversies. Cold Spring Harbor Perspect Biol. 2015;7(8):a020537-a.

58. Uhlen P, Fritz N, Smedler E, Malmersjo S, Kanatani S. Calcium signaling in neocortical development. Dev Neurobiol. 2015;75(4):360-8.

59. Uhlen P, Burch PM, Zito Cl, Estrada M, Ehrlich BE, Bennett AM. Gain-offunction/Noonan syndrome SHP-2/Ptpn11 mutants enhance calcium oscillations and impair NFAT signaling. Proc Natl Acad Sci U S A. 2006; 103(7):2160-5.

60. Pinzon A, Calancie B, Oudega M, Noga BR. Conduction of impulses by axons regenerated in a Schwann cell graft in the transected adult rat thoracic spinal cord. J Neurosci Res. 2001;64(5):533-41.

61. Akiyama Y, Radtke C, Kocsis JD. Remyelination of the rat spinal cord by transplantation of identified bone marrow stromal cells. J Neurosci. 2002; 22(15):6623-30.

62. Nashmi R, Velumian AA, Chung I, Zhang L, Agrawal SK, Fehlings MG. Patchclamp recordings from white matter glia in thin longitudinal slices of adult rat spinal cord. J Neurosci Methods. 2002;117(2):159-66.

63. Emgard M, Piao J, Aineskog H, Liu J, Calzarossa C, Odeberg J, et al. Neuroprotective effects of human spinal cord-derived neural precursor cells after transplantation to the injured spinal cord. Exp Neurol. 2014;253:138-45.

64. Åkesson E, Kjaeldgaard A, Seiger A. Human embryonic spinal cord grafts in adult rat spinal cord cavities: survival, growth, and interactions with the host. Exp Neurol. 1998;149(1):262-76.

65. Akesson E, Holmberg L, Jonhagen ME, Kjaeldgaard A, Falci S, Sundstrom E, et al. Solid human embryonic spinal cord xenografts in acute and chronic spinal cord cavities: a morphological and functional study. Exp Neurol. 2001; 170(2):305-16

66. Iwasaki M, Wilcox JT, Nishimura Y, Zweckberger $K$, Suzuki H, Wang J, et al. Synergistic effects of self-assembling peptide and neural stem/progenitor cells to promote tissue repair and forelimb functional recovery in cervical spinal cord injury. Biomaterials. 2014;35(9):2617-29.

67. Yousefifard M, Rahimi-Movaghar V, Nasirinezhad F, Baikpour M, Safari S, Saadat S, et al. Neural stem/progenitor cell transplantation for spinal cord injury treatment; a systematic review and meta-analysis. Neuroscience. 2016; 322:377-97.

\section{Publisher's Note}

Springer Nature remains neutral with regard to jurisdictional claims in published maps and institutional affiliations.

Ready to submit your research? Choose BMC and benefit from:

- fast, convenient online submission

- thorough peer review by experienced researchers in your field

- rapid publication on acceptance

- support for research data, including large and complex data types

- gold Open Access which fosters wider collaboration and increased citations

- maximum visibility for your research: over $100 \mathrm{M}$ website views per year

At BMC, research is always in progress.

Learn more biomedcentral.com/submissions 